\title{
CAMA
}

Centre for Applied Macroeconomic Analysis

\section{Small Firms and Domestic Bank Dependence in Europe's Great Recession}

\section{CAMA Working Paper 76/2019 October 2019}

Mathias Hoffmann

University of Zurich

CESifo

Centre for Applied Macroeconomic Analysis, ANU

\section{Egor Maslov}

University of Zurich

\section{Bent E. Sørensen}

University of Houston

CEPR

\section{Abstract}

Small businesses (SMEs) depend on banks for credit. We show that the severity of the Eurozone crisis was worse in countries where firms borrowed more from domestic banks ("domestic bank dependence") than in countries where firms borrowed more from international banks. Eurozone banking integration in the years 2000-2008 mainly involved cross-border lending between banks while foreign banks' lending to the real sector stayed flat. Hence, SMEs remained dependent on domestic banks and were vulnerable to global banking shocks. We confirm, using a calibrated quantitative model, that domestic bank dependence makes sectors and countries with many SMEs vulnerable to global banking shocks. 


\section{Keywords}

Small and medium enterprises, SME access to finance, Banking integration, Domestic bank dependence, International transmission, Eurozone crisis

\section{JEL Classification}

F30, F36, F40, F45

Address for correspondence:

(E) cama.admin@anu.edu.au

ISSN 2206-0332

The Centre for Applied Macroeconomic Analysis in the Crawford School of Public Policy has been established to build strong links between professional macroeconomists. It provides a forum for quality macroeconomic research and discussion of policy issues between academia, government and the private sector.

The Crawford School of Public Policy is the Australian National University's public policy school, serving and influencing Australia, Asia and the Pacific through advanced policy research, graduate and executive education, and policy impact. 


\title{
Small Firms and Domestic Bank Dependence in Europe's Great Recession
}

\author{
Mathias Hoffmann (University of Zurich \& CESifo) \\ Egor Maslov (University of Zurich) \\ Bent E. Sørensen (University of Houston \& CEPR) ${ }^{*}$
}

4th October 2019

\begin{abstract}
Small businesses (SMEs) depend on banks for credit. We show that the severity of the Eurozone crisis was worse in countries where firms borrowed more from domestic banks ("domestic bank dependence") than in countries where firms borrowed more from international banks. Eurozone banking integration in the years 2000-2008 mainly involved cross-border lending between banks while foreign banks' lending to the real sector stayed flat. Hence, SMEs remained dependent on domestic banks and were vulnerable to global banking shocks. We confirm, using a calibrated quantitative model, that domestic bank dependence makes sectors and countries with many SMEs vulnerable to global banking shocks.

Keywords: SMALl AND MEdiUm ENTERPRISES, SME ACCESS TO FINANCE, BANKING INTEGRATION, DOMESTIC BANK DEPENDENCE, INTERNATIONAL TRANSMISSION, EUROZONE CRISIS

JEL-Codes: F30, F36, F40, F45
\end{abstract}

\footnotetext{
*This project started as part of the European Commission's 2014-15 Fellowship initiative. We gratefully acknowledge comments from workshop participants during the various conferences of the fellowship program as well as at Humboldt University, the EEA meetings 2019, the annual meeting of the Verein für Socialpolitik, the ADEMU network workshop on "Risk Sharing Mechanisms for the European Union" at the European University Institute, T2M conference in Lisbon 2017 and IFABS 2017 conference in Oxford. We are particularly grateful to Nir Jaimovich, Kari Korhonen, Karl Pichelmann, Elias Papaiannou, and Michael Thiel for discussions and comments.

${ }^{\dagger}$ Mathias Hoffmann is at the University of Zurich, Dept. of Economics, International Trade and Finance Group, Zürichbergstrasse 14, CH-8032 Zürich. He is also affiliated with University of Zurich's Research Priority Program in Financial Market Regulation (URPP FinReg), the CESifo Munich and the Centre for Applied Macroeconomic Analysis (CAMA) at the Australian National University. E-mail: mathias.hoffmann@uzh.ch Egor Maslov is at the University of Zurich, Dept. of Banking and Finance. He is also affiliated with University of Zurich's Research Priority Program in Financial Market Regulation (URPP FinReg) and Swiss Finance Institute (SFI). E-mail: egor.maslov@bf.uzh.ch

Bent E. Sørensen is with the Dept. of Economics, University of Houston, Houston, TX, USA. He is also affiliated with the Centre for Economic Policy Research (CEPR). E-mail: besorensen@uh.edu
} 


\section{Introduction}

Since the inception of the Euro until 2008, cross-border bank lending in the Eurozone increased considerably but mainly took the form of cross-border lending to banks, while cross-border bank lending to the non-bank sector hardly increased. Thus, the real economy in most member countries remained dependent on the provision of credit by domestic banks. This pattern-which we refer to as "domestic bank dependence"-implied that the growth in domestic credit to the real sector in the years before the crisis was financed mainly by domestic banks, which in turn funded themselves through cross-border interbank borrowing. During the Eurozone crisis cross-border interbank lending declined sharply, while cross-border bank lending to the real sector remained relatively stable. This left economies and sectors that were reliant on domestic banks for finance particularly exposed to the global retrenchment in cross-border interbank lending. In this paper we provide empirical evidence consistent with this mechanism and propose a model which explains how the global retrenchment in cross-border interbank flows disproportionately affects countries with a high share of domestic banks and sectors with many small and medium-sized firms (SMEs). We show that our model produces predictions that qualitatively and quantitatively match the documented empirical patterns and that no other alternative scenarios we consider can by themselves replicate these findings.

We expect that sectors and countries with many SMEs would be particularly dependent on domestic banks for the provision of credit because SMEs are generally too small and too opaque to borrow from banks in other countries or from the bond market. Domestic banks generally have better information about local small firms and often engage in long-term relationships with their borrowers. This allows SMEs to satisfy their demand for finance that is not easily available from big foreign banks that mainly lend at arms-length. On the other hand, domestic bank dependence makes small firms particularly vulnerable to shocks that affect the domestic banking sector. Due to their relative opaqueness, SMEs can only imperfectly substitute other sources of credit for their domestic (often local) bank loans. Consistent with this firm-borrowing channel, we find empirically that the decline in crossborder interbank lending had larger negative real effects on output in countries with high domestic bank dependence, in particular in sectors with many SMEs.

In order to provide a fully articulated interpretation of our findings, we build a dynamic stochastic general equilibrium (DSGE) model. The model allows for both global and domestic ("local") banks and includes two sectors: a sector populated by "small" firms, which are reliant on borrowing from local banks, and a sector populated by "large" firms, which can satisfy a larger portion of their borrowing needs from global banks. Global banks, in contrast to local banks, do not satisfy the funding needs of firms (especially, small firms) completely and, as a result, firms have to borrow some funds from local banks, giving rise to "domestic bank dependence" in our model. Local banks collect deposits from their home 
country, but can also fund themselves in the European cross-border interbank market by borrowing from global banks, which in turn refinance themselves through wholesale funding in the global interbank market (the U.S.).

The baseline simulations of our model posit that the global financial crisis corresponds to a period of a large contraction of cross-border funding available to banks while TFP or local credit supply did not decline. The central assumption of our model is that banks actively adjust their risk-weighted leverage ratio as documented by Adrian and Shin (2014). Under this assumption, cross-border lending to banks contracts more than cross-border lending to the real sector following a global deleveraging shock. This is because profit-maximizing banks shift lending to high-return activities that have high regulatory risk weights, in particular lending to firms. This benefits larger firms, but as the contraction in cross-border interbank lending reduces local banks' lending capacity, it disproportionately hurts SMEs which are particularly dependent on local banks. The model is able to replicate these patterns in the data and therefore provides a structural interpretation.

We examine if our central interpretation is robust to a number of other features of the model. We consider alternative specifications for shocks in the crisis period, where we mute the global bank shocks and instead allow for either a concomitant drop in TFP in all countries, a synchronized drop in TFP in (model countries designed to match) the southern European countries Greece, Italy, Ireland, Greece, and Spain (GIIPS), or a synchronized rise in a refinancing cost for local banks in the GIIPS countries during the crisis. Results from simulations with TFP shocks, synchronized regionally or globally, do not explain the patterns in the data, as the model delivers coefficients of interest that are either zero or of the wrong sign. ${ }^{1}$ We interpret this as evidence that a synchronized drop in demand for loans from local banks does not provide an alternative explanation in conjunction with active leverage adjustment. Finally, results from simulations with synchronized local banking shocks also have a hard time matching the data, as the main coefficient of interest under this scenario is noisily estimated, albeit close in magnitude to the coefficient we get in the baseline case. This suggests that local credit supply shocks transmit to the real sector through a mechanism similar to that of global banking shocks, but that the degree of synchronization of these shocks needs go well beyond the GIIPS countries, effectively needing to be pan-European in order to match the data. Thus, although we find more support for the global nature of the retrenchment in cross-border interbank lending than local crises, the exact source of the bank credit supply shocks is irrelevant for our key finding that interbank integration leaves countries more exposed to banking sector shocks than direct banking integration,

\footnotetext{
${ }^{1}$ Brunnermeier and Reis (2019) explain how liquidity dried up in the Great Recession and its aftermath. They also point out that banks have migrated their liabilities from traditional deposit taking to a mixture of deposits, repos, and wholesale funds while assets have shifted from government bonds, loans, and mortgages to include a sizable fraction of tradeable assets. Many banks held domestic tradeable assets and in crisishit countries these assets lost value, causing banks to lose equity. This loss of equity would reinforce the contraction in lending that we model and our model permutation that allows for synchronized shocks in GIIPS countries is designed to capture such effects in reduced form.
} 
with sectors with many SMEs being particularly exposed.

The remainder of the paper is structured as follows: Section 2 provides a first look at the data and some initial stylized facts. Section 3 places our analysis in the context of the literature. Section 4 uses a stylized theoretical framework to motivate our empirical specifications that allow us to study the transmission of the financial crisis across countries on real data. Our DSGE model is laid out and brought to the data in Section 5, while Section 6 summarizes the quantitative results obtained from model simulations. Section 7 offers conclusions.

\section{A look at the data}

It is commonly observed that the European Monetary Union has given a boost to banking integration in Europe. Figure 1, which is based on locational banking statistics from the Bank for International Settlements (BIS), displays lending by foreign banks for a range of EMU countries, separately and combined (EMU-11). Flows of bank loans surged in the first decade of the EMU, but most of this growth was due to increased foreign bank lending to domestic banks-foreign bank lending to the domestic non-bank sector (which here includes the domestic private sector and government) increased less and has remained relatively flat. We argue that foreign lending to domestic banks versus lending to the non-bank sector are not simple substitutes, and, indeed, foreign lending to the non-bank sector generally proved resilient during the financial and sovereign debt crisis while bank-to-bank lending virtually imploded. The synchronization of the collapse in cross-border bank-tobank lending is noteworthy in this context. Even though countries' post-2008 experiences varied considerably in terms of the severity of banking and sovereign crisis and in their real effects, the initial trigger (the U.S. subprime crisis spilling over to Europe and leading to a worldwide crisis in interbanking markets) can be seen as a common factor which had differential impacts across countries, depending on their pre-existing vulnerabilities.

Figure 1 sets the scene for our empirical analysis. Banking sector integration in Europe was lopsided in the sense that there was too little real banking integration: the real sector was unable to diversify its sources of finance away from domestic banks. Domestic real-sector lending continued to be financed by domestic banks, which fund themselves by borrowing from foreign banks. This led to the pattern we observe in the data, with the growth in cross-border lending driven by bank-to-bank lending. ${ }^{2}$ We illustrate these two different concepts of banking integration in Figure 2. There are two countries, one referred to as the core country, and the other as the periphery country. The thick red arrow indicates the large cross-border banking flows in the data, whereas the thin grey arrows indicate the small flows of foreign bank lending from each country's banks to the other country's real

\footnotetext{
${ }^{2}$ Specifically, banks in the EMU periphery countries mainly borrowed from banks located in core economies which in turn borrowed in the U.S. money market (Hale and Obstfeld (2016)).
} 
sector. As was the case in the EMU before the crisis, net bank-to-bank flows were largely in the direction of the periphery country. The graph illustrates that, in the absence of direct cross-border real sector lending (thin or absent grey arrows), and in spite of high levels of bank-to-bank integration (thick red arrows between the two countries' banking sectors), the periphery remains vulnerable to both international liquidity shocks and domestic real shocks. ${ }^{3}$ This happens for two reasons: first, domestic banks have domestically concentrated asset portfolios, which make them vulnerable to any real-sector shocks in the home economy. Second, an international world-wide funding shock to banks in the periphery country may cut off bank credit supply to the domestic real sector. ${ }^{4}$

Figure 2 suggests that the impact of a domestic banking sector shock on the domestic economy will depend on the extent to which real sector credit is provided by domestic banks. As a measure of domestic bank dependence in country $c$-abbreviated as $\mathrm{DBD}^{c}-\mathrm{we}$ propose the share of total real sector credit that is provided by domestic banks:

$$
\operatorname{DBD}^{c}=\frac{\text { Domestic bank lending to the real private sector in country } c}{\text { Total credit to the real private sector in country } c} .
$$

We construct $\mathrm{DBD}^{c}$ using data from the Private Sector Credit Database (PSCD) compiled by the BIS. This database contains detailed information by country on the borrowing sector and the source of credit (domestic banks and foreign banks as well as debt securities). In the PSCD, the private sector comprises private non-financial corporations, households, and non-profit institutions serving households. The database rests on multiple data sources (national accounts, monetary surveys, and the BIS banking statistics) and has some gaps in its country coverage, which generally limits our European sample in the remainder of the paper to 11 Eurozone countries (Austria, Belgium, Finland, France, Germany, Greece, Ireland, Italy, the Netherlands, Portugal, and Spain). The data is quarterly and starts in the first quarter of 1997. We therefore limit all of our data to the time period 1997Q1-2013Q4 in order to focus on the period of the Eurozone crisis and the preceding years. We obtain a time-invariant (pre-crisis) measure for $\mathrm{DBD}^{c}$ by taking pre-2008 averages for each country.

Because we construct $\mathrm{DBD}^{c}$ as a pre-crisis average, it is an ex ante measure of how exposed aggregate credit supply in a country was to domestic banking sector shocks at the beginning of the Great Recession. The real effects in terms of output, consumption, or employment of any given drop in credit supply will depend on how elastic the private sector is in its choice of financing source. Figure 3 provides data from the 2011 edition of the European Central Bank's and EU Commission's Survey of Access to Finance by Enterprises (SAFE) on sources of external finance of SMEs (defined as firms with fewer than 250 employ-

\footnotetext{
${ }^{3}$ As pointed out by Morgan, Rime and Strahan (2004), financial integration provides insurance against local liquidity shocks, because international lending quickly can replace local lending as long as the return to local investment remains high.

${ }^{4}$ For example, this could be the case in a global banking crisis when cross-border bank lending-which is arguably much more short-term than cross-border bank-to-real sector lending-dries up.
} 
ees). The figure illustrates that bank loans are by far the most important source of external finance for SMEs in most countries.

We would therefore expect that SMEs during the crises were strongly affected in countries with high domestic bank dependence. Figure 4 provides prima facie evidence that this is the case. The first panel plots the share of SMEs that reported problems with obtaining external finance against country-level banking dependence $\left(\mathrm{DBD}^{c}\right)$. The second panel plots the share of firms reporting increased interest expenses minus the share of firms reporting decreased expenses against $\mathrm{DBD}^{c}$. The two plots deliver the same message: in countries with high levels of domestic bank dependence, the impact of the crisis on the financial situation of SMEs was worse.

In the remainder of the paper, we examine in more detail the patterns outlined in this section. In particular, we estimate how cross-country variation in domestic bank dependence interacted with cross-country and cross-sectoral variation in SME shares in the international transmission of the common shock presented by the financial crisis.

\section{Related literature}

Our analysis draws on several strands of the literature. The first strand concerns the role of banking integration in the transmission of macroeconomic shocks. Here, we also connect to the literature on the global financial cycle, which examines how changes in global financial conditions lead to heterogeneous, but highly synchronized, real outcomes across countries. The second strand encompasses recent empirical work that emphasizes the particular financing constraints faced by small firms during the European financial and sovereign debt crisis.

Regarding the empirical literature on the international transmission of banking sector shocks, we build on Peek and Rosengren (1997, 2000), who show how the burst of Japan's property bubble in the 1990s was reflected in Japanese banks contracting lending in the United States. Imai and Takarabe (2011) use a similar approach to study how the same shock spread across Japan's prefectures. Our paper is also related to work by Cetorelli and Goldberg $(2012 a, b)$ in its emphasis on the role of global banks' internal capital markets in international transmission and to Kalemli-Ozcan, Papaioannou and Peydro (2013) and KalemliOzcan, Papaioannou and Perri (2013), who show that the impact of banking integration on business cycle synchronization differs between crisis and tranquil periods. By illustrating how the international financing structure of an economy affects the transmission of global financial shocks, we also make contact with the literature on the global financial cycle (Rey (2015); Bruno and Shin (2015a))

Recent papers that have recognized the role of the particular financing constraints faced by SMEs during the Eurozone crisis include Ferrando and Mulier (2015) and Ferrando, Popov and Udell (2018). Ferrando and Mulier (2015) match SMEs' survey responses to bal- 
ance sheet information to check whether reported financial constraints line up with balance sheet facts. Our analysis is also close to Ferrando, Popov and Udell (2018), who use firmlevel data to document that SME-financing constraints are exacerbated in countries which were under macroeconomic and sovereign risk "stress" during the financial crisis.

Different from the studies discussed so far, our analysis of international transmission focuses on the interaction of SME prevalence and the nature of banking integration in the Eurozone, with its focus on bank-to-bank integration as a key factor in the transmission of the crisis across countries, regions, and sectors. ${ }^{5}$ A starting point for our analysis is the observation by Hale and Obstfeld (2016) that the inception of the Euro changed the geography of international banking flows. Global European banks head-quartered in the northern core countries started to intermediate funds from the global (dollar) interbank market to the European periphery. We focus on the fact that this lending boom mainly took the form of bank-to-bank lending while direct (bank-to-nonbank) lending from northern European core countries to the periphery increased much less.

Our emphasis on the differential impact of international and domestic bank lending on sector-level growth during the Eurozone crisis closely connects our work to that of Schnabel and Seckinger (2015). While Schnabel and Seckinger (2015) focus on external finance dependence in the sense of Rajan and Zingales (1998), we draw attention to firm size and the particular dependence of small firms on the local provision of credit as a key friction. The empirical framework for our analysis heavily draws on earlier work by one of us: Hoffmann and Okubo (2017) find that mechanisms, similar to the ones we document for Europe, were at work during Japan's lost decade.

Our paper also relates closely to work at the International Monetary Fund (2015), which emphasizes the different impacts that cross-border and direct local lending by foreign banks have on financial stability. We add to this by focusing on how international lending has affected real outcomes during the crisis in the Eurozone and by highlighting that it is important to distinguish between international bank-to-bank and bank-to-real sector lending. In this context, we also connect to a paper by Martinez (2015), who documents the role of cross-border bank-to-bank lending in fueling boom and bust cycles.

Our empirical findings are rationalized and evaluated within a DSGE model. This model builds on Kalemli-Ozcan, Papaioannou and Perri (2013) and extends it along several dimensions. First, we introduce an interbanking market to allow for a distinction between crossborder lending to banks and the real sector. Second, we introduce a non-tradeable sector populated by SMEs that borrow from global banks and local domestic banks. The latter, in turn, fund themselves from global banks in the interbank market. We use this model to replicate the stylized facts that we document in our empirical analysis.

\footnotetext{
${ }^{5}$ We do not evaluate the benefits from integrated cross-border lending to banks relative to the more fragmented markets that existed before the introduction of the euro. See the survey of Sørensen and VillegasSanchez (2015) for the benefits of financial integration in the absence of market imperfections.
} 
Our model also relates to Kollmann, Enders and Müller (2011), Kollmann (2013), Bruno and Shin (2015b) and Kerl and Niepmann (2015). Kollmann, Enders and Müller (2011) and Kollmann (2013) examine the role of global banks in global business cycle transmission. Our framework differs from theirs by allowing for different modalities of international bank lending-direct lending to firms by global banks vs. interbank lending-and by allowing for two sectors which differ in their financing needs. Bruno and Shin (2015b) formulate a model of "double-decker" banking integration by allowing global banks to interact with local banks, while Kerl and Niepmann (2015) explain the choice between direct and interbank cross-border lending as a function of barriers to entry into foreign banking markets. In our model, entry barriers take the form of frictions which give local banks an advantage in lending to SMEs and, because we embed direct and interbank cross-border bank lending into a fully dynamic model, we can study how the modality of cross-border bank lending affects the dynamics and transmission of macroeconomic shocks.

The idea that small firms rely on relationship lending and therefore require local access to credit is well-established in the banking literature. Starting with Berger and Udell (1995) a large literature shows that small firms are more likely to borrow from small, local banks which have a comparative advantage in relationship lending. Degryse and Ongena (2005) emphasize the role of distance for the intensity of banking relationships and for the intensity of banking competition. Mian (2006) provides empirical evidence on the role of foreign vs domestic banks in lending to small firms in the context of a developing economy. While long-standing banking relationships may help a firm to obtain credit more easily when facing adverse firm-specific shocks (Petersen and Rajan (1994)), relationship lending also creates a hold-up problem if a negative shock affects the lender. In this situation it may be difficult to turn to alternative sources of finance (Sharpe (1990)). Giannetti and Ongena (2007) show that the presence of foreign banks improves small firm access to credit. Our macroeconomic model captures these mechanisms in reduced form.

Starting with Khwaja and Mian (2008), the micro-banking literature has begun to explore the real effects of banking shocks in matched bank-firm-level data. In this paper, our interest is in understanding the macroeconomic relevance of the above mechanisms for the EMU as a whole. In particular, we are interested in how the structure of cross-border lending (interbank vs. direct lending to firms) affects the transmission of macroeconomic shocks. We are not aware of matched bank-firm level data sets that would allow us to study this nexus, i.e. that would be (a) representative at the level of individual countries (and in particular, would also cover small firms); (b) would allow us to distinguish between direct and indirect (via the impact of the interbank market on domestic banks) exposures of firms; and (c) at the same time would cover sufficiently many EMU countries. ${ }^{6}$ We therefore conduct

\footnotetext{
${ }^{6}$ To our knowledge, Hale, Kapan and Minoiu (forthcoming) is the first paper to examine the role of crossborder interbank exposures for firm-level lending, but their evidence is based on syndicated loan data and thus on big firms.
} 
our empirical analysis at the sector-country level, discussing identification assumption and potential challenges in detail. Then, building on the approach in Kalemli-Ozcan, Papaioannou and Perri (2013), we use our DSGE model to target the empirical specifications and as a laboratory in which we simulate the impact of confounding factors on our empirical results. This allows us to strike a balance between the high levels of internal validity achieved by the micro-banking literature and the external validity of a more macroeconomic approach.

\section{Domestic bank dependence and the transmission of the financial crisis across the Eurozone}

\section{Econometric specifications}

As starting point for our empirical analysis, we posit the following reduced-form link between fluctuations in domestic real sector credit and output growth:

$$
\Delta \log \mathrm{GVA}_{t}^{c, s}=\gamma^{c, s} \times \Delta \log \mathrm{CREDIT}_{t}^{c}+\eta_{t}^{c, s}
$$

where $\Delta \log \mathrm{GVA}_{t}^{c, s}$ is the growth rate of gross valued added in country $c$, in sector $s, \Delta \log \mathrm{CREDIT}_{t}^{c}$ is the growth of domestic credit to the real sector in country $c$, and $\eta_{t}^{c, s}$ is a productivity shock. This specification acknowledges that firms are heterogeneous in their ability to substitute fluctuations in the availability of bank credit for other forms of funding. ${ }^{7}$ We can think of the coefficient $\gamma^{c, s}$ as capturing this ability, which is likely to vary by sector and/or country. For instance, if $\gamma^{c, s}=0$, firms can fully offset variations in bank loan supply by turning to internal or non-bank finance (e.g., by issuing bonds). If $\gamma^{c, s}>0$, fluctuations in bank finance cannot be fully offset and will have real effects. Based on our earlier discussion, we conjecture that country-sectors with higher SME shares will be more sensitive to variation in lending growth, so that

$$
\gamma^{c, s}=\gamma_{0}+\gamma_{1} \times \mathrm{SME}^{c, s}
$$

where $\mathrm{SME}^{c, s}$ stands for the share of SMEs with less than 250 employees in value added in country $c$, sector $s$ in 2008, and where we expect that $\gamma_{1}>0$.

We next link domestic credit supply to shocks to cross-border bank lending. We interpret the financial crisis as a global shock to banks' lending capacity that, in principle, was common to all Eurozone countries, but that affected countries differently according to their dependence on domestic banks for finance. Based on this presumption, we conjecture the

\footnotetext{
${ }^{7}$ This is in the spirit of the literature on the firm-borrowing channel (e.g. Khwaja and Mian (2008)). However, unlike in most of that literature, for the reasons discussed in the previous section our focus here is on the country-sector rather than the bank-firm level.
} 
relation:

$$
\Delta \log \mathrm{CREDIT}_{t}^{c}=\operatorname{DBD}^{c} \times \Delta \mathrm{GBS}_{t}+\xi_{t}^{c},
$$

where $\mathrm{DBD}^{c}$ is our measure of domestic bank dependence, $\Delta \mathrm{GBS}_{t}$ is an indicator of the shock to the global banking sector, and $\xi_{t}^{c, s}$ is a country-sector specific credit demand shock.

Our hypothesis is that the global banking sector shock mainly manifested itself in a breakdown of cross-border lending between banks, whereas, as we have seen in Figure 1, direct cross-border bank lending to the real sector was much less affected. We therefore construct a measure $\Delta \mathrm{GBS}_{t}$, that captures bank-to-bank lending net of bank-to-nonbank lending, as

$$
\Delta \mathrm{GBS}_{t}=-\left[\Delta \log \mathrm{B} 2 \mathrm{~B}_{t}-\Delta \log \mathrm{B} 2 \mathrm{~N}_{t}\right],
$$

where $\mathrm{B}_{2} \mathrm{~B}_{t}$ and $\mathrm{B}_{2} \mathrm{~N}_{t}$ denote the total (in sample) cross-country volume of indirect (bankto-bank) and direct (bank-to-nonbank) cross-border lending, respectively. We construct $\Delta \mathrm{GBS}_{t}$ as the relative growth rates of bank-to-bank and bank-to-nonbank lending because our focus in this paper is on how the shift in the composition of cross-border lending asymetrically affected SMEs in economies dependent on domestic banks. Also, the drop in cross-border lending during the global financial crisis could have a large common component due to global drop in credit demand. To the extent that this drop affected foreign and domestic banks equally, relative growth rates of direct and indirect lending would eliminate this common demand component. We discuss this point more formally below.

Putting equations (1), (2) and (3) together, we obtain

$\Delta \log \mathrm{GVA}_{t}^{c, s}=\Delta \mathrm{GBS}_{t} \times\left[\alpha_{1} \mathrm{DBD}^{c} \times \mathrm{SME}^{c, s}+\alpha_{2} \mathrm{SME}^{c, s}+\alpha_{3} \mathrm{DBD}^{c}\right]+$ CONTROLS $+\tau_{t}+\mu^{c, s}+\varepsilon_{t}^{c, s}$,

which is our main empirical specification. The coefficient of interest is $\alpha_{1}$ and we expect $\alpha_{1}<0$ : the global banking sector shock should have particularly adverse effects in countries and sectors that are particularly dependent on domestic banks for credit provision, because they have a high share of SMEs.

To see how our approach achieves identification of $\alpha_{1}$, we note first that $\Delta \mathrm{GBS}_{t}$ is an aggregate ("world"-wide) variable and is therefore uncorrelated with purely local (countryand/or sector-specific) credit demand shocks. As is easy to verify, the residual term can be written as $\varepsilon_{t}^{c, s}=\gamma^{c, s} \times \xi_{t}^{c, s}+\eta_{t}^{c, s}$. This term absorbs country-sector specific components of credit demand that are orthogonal to $\Delta \mathrm{GBS}_{t}$, while the effects of $\Delta \mathrm{GBS}_{t}$ that are common to all country-sectors (as well as any other common factor with homogeneous effects across country-sectors) will be absorbed by the time effect, $\tau_{t}{ }^{8}$

One remaining challenge to identification is that we are neglecting unobserved common factors that may be correlated with $\Delta \mathrm{GBS}_{t}$ and that also differ in their impact across

\footnotetext{
${ }^{8} \mathrm{Because} \mathrm{SME}^{c, s}$ and $\mathrm{DBD}^{c}$ are time-invariant in our estimation, their respective first-order effects will be absorbed by the country-sector fixed effects, $\mu^{c, s}$. In addition, several versions of the main regression that we present below will also control for country-time and sector-time effects.
} 
countries and sectors in a way that is correlated with the country-sector variation in $\mathrm{DBD}^{c} \times$ $\mathrm{SME}^{c, s}$. To see this, let $f_{t}$ be a potential un-modelled factor which loads on output in countrysector $c, s$ with loading $\delta^{c, s}$. Then, whenever $\operatorname{cov}\left(f_{t}, \Delta \mathrm{GBS}_{t}\right) \neq 0$, we need to assume that the cross-sectional covariance $\operatorname{cov}\left(\delta^{c, s}, \operatorname{DBD}^{c} \times \operatorname{SME}^{c, s}\right)$ equals zero. ${ }^{9}$

The assumption $\operatorname{cov}\left(\delta^{c, s}, \mathrm{DBD}^{c} \times \mathrm{SME}^{c, s}\right)=0$ might be violated if, during the global financial crisis, there was also an aggregate (EU-wide or global) decline in the demand for loans. This decline plausibly could have been strongest in countries with high local bank dependence and in sectors that have many SMEs that mainly serve local markets. Our measure of the global banking-sector shock addresses this concern by focusing on the difference in growth rates between cross-border bank-to-bank and bank-to-nonbank lending. To the extent that a global credit-demand shock affects the two forms of lending symmetrically, their difference is left to capture shocks that are specific to the global banking sector and thus mainly to the credit supply-side. Our theoretical model below will allow us to quantitatively explore whether this identifying assumption is justified.

\section{Data}

To implement the above regressions, we measure output growth using quarterly data on gross value added at the sectoral level from Eurostat. ${ }^{10}$ For all output measures, we obtain real per capita values by deflating with the respective sectoral deflators and using population data from the same source. Because quarterly data can be noisy, we study annual growth rates of all variables (notably real per capita GVA) by taking differences between quarter $t$ and $t-4$, so that $\Delta \log \mathrm{GVA}_{t}^{c, s}=\log \mathrm{GVA}_{t}^{c, s}-\log \mathrm{GVA}_{t-4}^{c, s}$ throughout the paper.

While $\mathrm{DBD}^{c}$ is constructed in the way already described in Section 2, our data on SME importance is from the 2018 issue of the annual database accompanying the European Commissions' SME performance review. ${ }^{11}$ Specifically, we construct our measure SME ${ }^{c, s}$ as the share in value added at factor costs (million euros at current prices) at the country-sector level of firms with fewer than 250 employees. While the values for $\mathrm{DBD}^{c}$ are constructed as pre-2008, within-country averages, data on the value added of small businesses is not generally available before 2008 . We therefore use the 2008 values to construct $\mathrm{SME}^{c, s}$.

\footnotetext{
${ }^{9}$ See Hoffmann and Okubo (2017) for a detailed discussion.

${ }^{10}$ Sectoral gross value added is obtained from Eurostat's Gross value added and income $A^{*} 10$ industry breakdowns (namq_10_a10). We drop agriculture, finance and insurance, and public administration and limit our sample to six sectors (1-digit NACE rev 2 codes in parentheses) for which we also have data on the corresponding SME shares: industry except construction (BCDE), construction (F), wholesale and retail + transport and storage + accomodation and food services (GHI), information and communication (J), real estate (L), and professional activities + administrative and support services (MN).

${ }^{11}$ https://ec.europa.eu/growth/smes/business-friendly-environment/performance-review_en
} 


\section{Main empirical results}

The results of the baseline country-sector level specifications (4) are summarized in Table 1. Consistent with our theoretical interpretation, the main coefficient of interest, $\alpha_{1}$, is negative and significant throughout. The first column of the table shows the results for all countries. The following columns examine the sensitivity of our results to the exact sample of countries. Specifically, we augment the baseline specification to include a dummy for the EMU core economies (Belgium, France, Germany, and the Netherlands) or a dummy for Greece in the interactions with the crisis indicator.

In all specifications, the coefficient $\alpha_{1}$ stays negative, significant and quite stable relative to the baseline estimate in the first column. The results suggest that dependence on domestic banks for finance was detrimental mainly for country-sectors with many SMEs. The standalone terms for $\mathrm{SME}^{c, s}$ and $\mathrm{DBD}^{c}$ are insignificant across almost all specifications. This suggests that for the average country-sector an increase (decrease) in the SME share or a lower dependence on domestic banks does not unambiguously lead to higher or lower growth. Rather, it seems that the real effects of the global banking shock are robustly modulated through the interaction between these two variables.

In Table 2, we subject our country-sector level regressions to further robustness checks. In the first two columns, we add, in turn, sector-time and country-time effects, in addition to the country-sector and time effects that were already included in the previous specifications. Our estimate of $\alpha_{1}$ stays negative in both specifications and remains significant. This is also true for a fully saturated specification in which we include both country-time and sectortime effects. We also run a version of our regression, in which we split the sample of countrysectors into high (above-median) and low (below-median) shares of SMEs. Again, our results hold up. This regression, reported in column (4), will be our main reference point when comparing the DSGE model that we present in the next section to the regressions results based on actual data. In the DSGE model, within each country, there are two sectors: one populated only by SMEs and one populated only by large firms. This setup directly maps into the specification reported in column (4) of Table 2, where sectors are coded as being SMEintensive (or not) using a dummy. The economic magnitude of the results is large. A one standard deviation shock to $\Delta \mathrm{GBS}_{t}(0.09)$ in a country with a domestic bank dependence one standard deviation (0.13) above the sample average results in a 0.5 percentage points larger drop in gross value added in high SME sectors compared with low SME sectors $(0.005 \approx$ $0.43 \times 0.09 \times 0.13)$.

The last two columns of Table 2 show that our findings hold up even in the crosssection: column (5) presents a cross-sectional regression of the post-2008 drop in sectoral GVA growth on 2008 SME shares and the interaction of SME with local bank dependence, while column (6) repeats the before-after regression, but now coding the SME share as high or low, as in the panel regression in column (4). The result with high-low SME dummy re- 
mains significant and economically large: the decline in average growth rate in gross value added in the crisis period for a country with a domestic bank dependence one standard deviation (0.13) above the sample average is 1.3 percentage points stronger in high SME sectors compared with low SME sectors $(0.013 \approx 0.009 \times 0.13) .{ }^{12}$

Figure 5 visualizes the results from the before-after regression in column (6). For each country, it plots the difference between post-2008 and pre-2008 sectoral growth rates against the pre-2008 levels of domestic bank dependence. Sectors with above-median shares of SMEs appear as red dots and those with below-median shares of SMEs appear as blue diamonds. Across the whole sample, the link between growth and SME shares seems weak; however, once we distinguish between high and low levels of SME shares, we find that there is a clear negative link between growth and domestic bank dependence in country-sectors with high SME shares. This negative link is much weaker for low-SME sectors.

We also study the dynamic response of real activity to the global banking sector shock. To this end, we split the sample in two groups: country-sectors with above-median shares of SMEs and country-sectors with low SME shares. For each group, we then estimate local linear projections of the form:

$$
\log \mathrm{GVA}_{t+h}^{c, s}-\log \mathrm{GVA}_{t-1}^{c, s}=\alpha_{h} \times \mathrm{DBD}^{c} \times \Delta \mathrm{GBS}_{t}+\tau_{t}+\mu^{c, s}+\varepsilon_{t+h}^{c, s},
$$

at horizons of $h=0,1, \ldots, 4$ years. Local linear projections (LLP) were first proposed by Jordà (2005) and capture the dynamics of the dependent variable in a very general way. While conceptually similar to impulse responses, LLP do not require the underlying data generating process to be linear.

Figure 6 plots the coefficients $\alpha_{h}$ up to horizon of 4 years for our country-sector data set (reflecting the effects on cumulative GVA growth) separately for high (red lines) and low (blue lines) SME country-sectors. Shaded areas indicate corresponding 90\% confidence bands, constructed with standard errors clustered by country and time. For the high-SME sectors, the effect of high domestic bank dependence is highly persistent and statistically significant, accumulating to an output loss of around 1.5 percent over five years to a one standard deviation shock to $\Delta \mathrm{GBS}_{t}(0.09)$ for a country with a domestic bank dependence one standard deviation $(0.13)$ above the sample average $(0.015 \approx 1.25 \times 0.09 \times 0.13)$. For the low-SME sectors, there is virtually no effect.

\footnotetext{
${ }^{12}$ As pointed out by Bertrand, Duflo and Mullainathan (2004), panel diff-in-diff regressions such as our baseline specifications can be spuriously significant if there is essentially only one common treatment (in our case: the crisis). They therefore recommend a "before-after" cross-sectional regression such as the one presented here as a robustness check.
} 


\section{A theoretical model}

We propose a tractable DSGE model with local and global banks and two production sectors, which we use to interpret the empirical results. Specifically, the model formalizes the idea that bank-to-bank lending exposes local bank sectors to global banking sector shocks without reducing the exposure of the economy to idiosyncratic shocks.

\section{Agents and markets}

There are two open economies in our model, each populated by a representative household, a big firm producing tradeable goods, a small firm producing non-tradeable goods, and a local bank. ${ }^{13}$ The (small) home country represents one of the 11 EMU countries in our sample, while the (large) foreign one represents the "rest of the EMU." Additionally, there is a global bank, which operates in the two countries (EMU) and has access to wholesale funding in the rest of the world (e.g., the U.S. money market).

Firms Firms in sector $s=\{\mathrm{BF}, \mathrm{SME}\}$ (BF refers to big firms and SME to SMEs) have the production function:

$$
Y_{t}^{s}=\theta_{t}^{s}\left(K_{t-1}^{s}\right)^{\alpha^{s}}\left(N_{t}^{s}\right)^{1-\alpha^{s}}
$$

where, for sector $s, Y_{t}^{s}, \theta_{t}^{s}, K_{t-1}^{s}, N_{t}^{s}$ and $\alpha^{s}$ denote output, total factor productivity, capital (at the end of the previous period), labor, and capital intensity, respectively. Firms in both sectors are owned by households, operate in a perfectly competitive environment, and maximize the present discounted value of their profits (dividends):

$$
\max _{\left\{N_{t}^{s}, K_{t}^{s}, L_{t}^{s}\right\}_{t=0}^{\infty}} \mathbb{E}_{0}\left[\sum_{t=0}^{\infty} \Lambda_{0: t} \mathrm{DIV}_{t}^{s}\right],
$$

where $\Lambda_{t: t+l}$ is the household stochastic discount factor at horizon $l$. Dividends are defined as:

$$
\operatorname{DIV}_{t}^{s}=P_{t}^{s} Y_{t}^{s}-W_{t} N_{t}^{s}-P_{t}\left(I_{t}^{s}+\varphi_{t}^{I, s}\right)+L_{t}^{s}-L_{t-1}^{s}\left(1+r_{t-1}^{l, s}\right)
$$

where $P_{t}^{s}$ denotes price of output in sector $s, P_{t}$ is the price of the final good, $W_{t}$ is wages, and $I_{t}^{s}$ is investment in sector $s .{ }^{14}$ Furthermore, $L_{t}^{s}$ denotes total sector $s$ borrowing and $r_{t}^{l, s}$ is the net effective interest rate paid by firms in sector $s$. The law of motion for sectoral capital is given by $K_{t}^{s}=(1-\delta) K_{t-1}^{s}+I_{t}^{s}$, and both capital and investment are produced

\footnotetext{
${ }^{13}$ The assumption that SMEs are all in the non-tradeable sector is inessential for our results and made here for convenience. However, it is consistent with the observation in the trade literature that smaller, less productive, firms are less likely to engage in international trade (Melitz (2003)). It is additionally supported by the results in the Survey of Access to Finance by Enterprises (SAFE), according to which ca. 60\% of the participating SMEs did not export any goods or services in 2014, and 22\% of the SMEs generate less than 25\% of their turnover in foreign markets.

${ }^{14}$ We normalize the price of tradeable goods to unity in both countries.
} 
out of the final good subject to a sector-specific quadratic adjustment cost in investment; i.e., $\varphi_{t}^{I, s}=\frac{1}{2} \varphi^{I} K_{t-1}^{s}\left(\frac{I_{t}^{s}}{K_{t-1}^{s}}-\delta\right)^{2}$.

Firms need to borrow in order to finance their operating expenses; i.e., the wage bill and investment. This setup follows Neumeyer and Perri (2005), who rationalize the wage bill pre-financing need of firms through within-period loans by the timing structure of wage contracts and firm production. We extend their argument along two dimensions. First, firms need to pre-finance investment outlays, and second, loans need to be repaid after dividends have been distributed. This makes firm loans intertemporal, which matches the timing of deposits and interbank loans in the economy. The identity for external finance is thus

$$
L_{t}^{s}=W_{t} N_{t}^{s}+P_{t} I_{t}^{s}
$$

Firms in both sectors have to bundle loans from global and local banks to satisfy their borrowing needs. Specifically, we posit the following borrowing technology:

$$
L_{t}^{s}=\left(\tau^{s \frac{1}{\nu}} L_{t}^{s, \mathrm{~GB} \frac{\nu-1}{\nu}}+\left(1-\tau^{s}\right)^{\frac{1}{\nu}} L_{t}^{s, \mathrm{LB} \frac{\nu-1}{\nu}}\right)^{\frac{\nu}{\nu-1}}
$$

where $L_{t}^{s, \mathrm{~GB}}$ and $L_{t}^{s, \mathrm{LB}}$ are sector $s$ borrowing from global and local banks, respectively, and $\tau^{s}$ captures the degree to which firms in sector $s$ depend on local bank credit (lower $\tau^{s}$ translating into higher dependence). Firms decide how much to borrow from global and local banks by minimizing the expected repayment $L_{t}^{s}\left(1+r_{t}^{l, s}\right)=L_{t}^{s, \mathrm{~GB}}\left(1+r_{t}^{l, s, \mathrm{~GB}}\right)+$ $L_{t}^{s, \mathrm{LB}}\left(1+r_{t}^{l, s, \mathrm{LB}}\right)$, subject to the borrowing technology. ${ }^{15}$

This setup implies that loans from local and global banks are imperfect substitutes, with an elasticity of substitution being captured by the parameter $\nu$. This is meant to reflect that global and local banks have different business models. Large international banks engage mainly in arm's-length lending, while local banks engage mainly in relationship-lending. During a long-term relationship local banks acquire information about the small firm. This leads to the well-known hold-up problem (Sharpe (1990) and Petersen and Rajan (1994)) and makes it difficult for the borrowing firm to move away from the local bank. Therefore, loans from global and local banks are imperfect substitutes from the point of view of the borrowing firm and compared to large firms, SMEs are more dependent on local banks $\left(\tau^{\mathrm{SME}}<\tau^{\mathrm{BF}}\right)$. The borrowing technology above captures these features in a reduced form.

Banks In each country, there is a local (domestic) bank. Additionally, local households own a constant fraction of the global bank. Local banks fund themselves by borrowing

\footnotetext{
${ }^{15} \mathrm{~A}$ similar approach to modeling the demand for loans is used by Gerali et al. (2010). However, they do not distinguish between different firm- or bank-types, which is one of the main distinct features of our model. Note also, that under the CES assumption, effective funds available to firms for productive purposes $\left(L_{t}^{s}\right)$ are less than or equal to the sum of loans extended to them by local and global banks $\left(L_{t}^{s, \mathrm{~GB}}+L_{t}^{s, \mathrm{LB}}\right)$. We interpret this discrepancy as an implicit borrowing cost.
} 
from global banks and through deposits, while global banks have access to funds in a global money market (which we do not model). This setup is meant to reflect the structure of the "double-decker" banking integration that was characteristic for the Eurozone in the years before the crisis, as documented by Bruno and Shin (2015b) and Hale and Obstfeld (2016). In particular, big French, German, and Dutch banks borrowed in the U.S. money market, while Southern European local banks borrowed short-term from the global northern European banks.

The local bank extends loans to small and large firms, $L_{t}^{\mathrm{SME}, \mathrm{LB}}$ and $L_{t}^{\mathrm{BF}, \mathrm{LB}}$, and raises funds in the European interbank market $\left(M_{t}\right)$ and in the form of domestic deposits $\left(D_{t}\right)$. Its balance sheet identity is correspondingly given by:

$$
L_{t}^{\mathrm{SME}, \mathrm{LB}}+L_{t}^{\mathrm{BF}, \mathrm{LB}}=M_{t}+D_{t} .
$$

The local bank is owned by domestic households and maximizes expected discounted profits. Because the bank's problem is effectively intratemporal, this amounts to maximizing (and fully disbursing) its profits $\left(\Pi_{t}^{\mathrm{LB}}\right)$ each period:

$$
L_{t}^{\mathrm{SME}, \mathrm{LB}}, \max _{L_{t}^{\mathrm{BF}, \mathrm{LB}}, M_{t}, D_{t}} \Pi_{t}^{\mathrm{LB}}
$$

where $\Pi_{t}^{\mathrm{LB}}=L_{t}^{\mathrm{SME}, \mathrm{LB}} r_{t}^{l, \mathrm{SME}, \mathrm{LB}}+L_{t}^{\mathrm{BF}, \mathrm{LB}} r_{t}^{l, \mathrm{BF}, \mathrm{LB}}-M_{t} r_{t}^{m}-D_{t} r_{t}^{d}-\varphi_{t}^{\mathrm{LB}}$ and $r_{t}^{l, \mathrm{SME}, \mathrm{LB}}$, $r_{t}^{l, \mathrm{BF}, \mathrm{LB}}, r_{t}^{m}$ and $r_{t}^{d}$ denote interest rates on local bank loans to small and large firms, the interbank lending rate, and the deposit rate, respectively. The last term, $\varphi_{t}^{\mathrm{LB}}$, is a quadratic "adjustment cost" in deposits, modeled as a function of the relative deviation of deposits from their long-run value, namely, $\varphi_{t}^{\mathrm{LB}}=\frac{1}{2} \varphi^{\mathrm{LB}} D\left(\frac{D_{t}-D}{D}\right)^{2}$. This term reflects the difficulty for banks to undergo short-term changes in their funding structure and prevents unit-root dynamics in deposits and interbank loans, known to be otherwise a feature of this type of models (Schmitt-Grohé and Uribe (2003)).

The global bank provides funds to small and large firms in both countries $\left(L_{t}^{\mathrm{SME}, \mathrm{GB}}\right.$ and $L_{t}^{\mathrm{BF}, \mathrm{GB}}$ ) and additionally lends an amount $M_{t}$ in the interbank market. It refinances itself through wholesale funding, $B_{t}$, in the global interbank market, such that its balance sheet is given by:

$$
L_{t}^{\mathrm{SME}, \mathrm{GB}}+L_{t}^{\mathrm{SME}, \mathrm{GB}^{*}}+L_{t}^{\mathrm{BF}, \mathrm{GB}}+L_{t}^{\mathrm{BF}, \mathrm{GB}^{*}}+M_{t}+M_{t}^{*}=B_{t},
$$

where an asterisk $\left(^{*}\right)$ indicates the foreign country. Its objective is to maximize total expected discounted profits. The global bank's problem is again intratemporal-as for the local bank-this amounts to maximizing profits $\left(\Pi_{t}^{\mathrm{GB}}\right)$ each period:

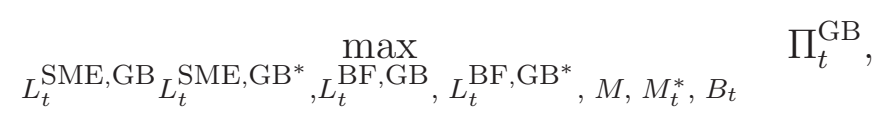


where

$$
\begin{aligned}
\Pi_{t}^{\mathrm{GB}}= & \left(L_{t}^{\mathrm{SME}, \mathrm{GB}}+L_{t}^{\mathrm{SME}, \mathrm{GB}^{*}}\right) r_{t}^{l, \mathrm{SME}, \mathrm{GB}}+\left(L_{t}^{\mathrm{BF}, \mathrm{GB}}+L_{t}^{\mathrm{BF}, \mathrm{GB}^{*}}\right) r_{t}^{l, \mathrm{BF}, \mathrm{GB}} \\
& +\left(M_{t}+M_{t}^{*}\right) r_{t}^{m}-B_{t} r_{t}^{b}-\varphi_{t}^{\mathrm{GB}}
\end{aligned}
$$

and where $r_{t}^{l, \mathrm{SME}, \mathrm{GB}}$ and $r_{t}^{l, \mathrm{BF}, \mathrm{GB}}$ denote interest rates on global bank loans to small and large firms, respectively, $r_{t}^{m}$ is the interbank lending rate, and $r_{t}^{b}$ is the cost of financing in the global interbank market. Because the global bank is owned in constant proportions by the home and foreign households, total profits $\Pi_{t}^{\mathrm{GB}}$ are disbursed to households in both countries based on ownership shares $\mu^{\mathrm{GB}}$ and $\mu^{\mathrm{GB} *}=1-\mu^{\mathrm{GB}} \cdot{ }^{16}$

The global bank is exposed to lending conditions in the rest of the world through exogenous fluctuations in the supply of funds offered in the global money markets. In particular, a drop in $B_{t}$ raises the global interest rate $r_{t}^{b}$, which transmits to lending conditions to firms and households in both countries. Adrian and Shin (2014) show that, at least in the years before the crisis, global banks adjusted leverage mainly via changes in riskweighted assets (RWA). We introduce this concept into our model via the adjustment cost in the bank's risk-weighted assets, namely, $\varphi_{t}^{\mathrm{GB}}=\varphi^{\mathrm{GB}} R W A\left(\frac{R W A_{t}-R W A}{R W A}\right)^{2}$, where we define the risk-weighted assets as $R W A_{t}=\gamma^{L}\left(L_{t}^{\mathrm{SME}, \mathrm{GB}}+L_{t}^{\mathrm{SME}, \mathrm{GB}^{*}}+L_{t}^{\mathrm{BF}, \mathrm{GB}}+L_{t}^{\mathrm{BF}, \mathrm{GB}^{*}}\right)+$ $\gamma^{M}\left(M_{t}+M_{t}^{*}\right)$, where $\gamma^{L}$ and $\gamma^{M}$ are the risk weightings associated with real-sector and bank-to-bank loans, respectively, and where $R W A$ denotes risk-weighted assets in the steadystate. Given differences in risk weightings on different assets, and in particular $\gamma^{L}>\gamma^{M}$, the global shock does not affect the interbank and real sector lending rates symmetrically, but causes a positive spread between them as the global bank rebalances its asset side away from (notionally) low-risk interbank loans towards (notionally) high-risk real sector loans.

The risk weights, $\gamma^{L}$ and $\gamma^{M}$ play a key role for the transmission of the global banking shock in our model. Under Basel II regulation, real sector financing is considered to be riskier than interbank loans or investments into highly-rated "risk-less" assets (among which mortgage-backed securities or southern European sovereign bonds used to be counted before the crisis). This implies that $\gamma^{L}>\gamma^{M}$ and the bank will have a higher shadow cost of real sector-loans and demand a higher interest rate. Assume that a global banking shock lets $B_{t}$ shrink to zero. As the bank's balance sheet shrinks, it can shift lending to higher interestrate real loans while still maintaining the level of risk-weighted assets-cross-border lending to banks declines relative to real sector lending, very much as we observe in the data.

Both global and local banks possess market power, as credit is extended to firms in a monopolistic competition environment. We do not explicitly model the microeconomic mechanism behind it and refer the reader to any model in which a Dixit-Stiglitz framework is applied to the bank loan market; e.g., Gerali et al. (2010). The implication of market power

\footnotetext{
${ }^{16}$ These ownership shares are calculated as long-run shares of revenues that the global bank earns in a re-

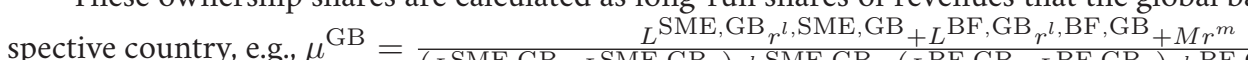

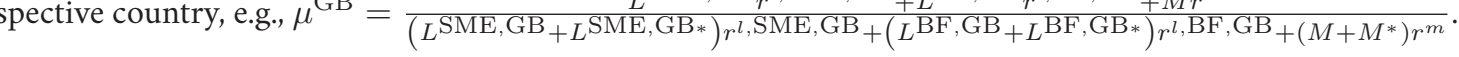


is that banks set mark-ups on their cost of funds when they extend credit to large and small firms.

The optimal supply of credit, arising from local and global bank optimization problems given the monopolistic competition and costly adjustment in risk-weighted assets is the following:

$$
\begin{gathered}
r_{t}^{l, \mathrm{SME}, \mathrm{GB}}=\left(r_{t}^{b}+\gamma^{L} \varphi^{\mathrm{GB}}\left(\frac{R W A_{t}-R W A}{R W A}\right)\right) \times M U^{\mathrm{SME}}, \\
r_{t}^{l, \mathrm{BF}, \mathrm{GB}}=\left(r_{t}^{b}+\gamma^{L} \varphi^{\mathrm{GB}}\left(\frac{R W A_{t}-R W A}{R W A}\right)\right) \times M U^{\mathrm{BF}}, \\
r_{t}^{m}=r_{t}^{b}+\gamma^{M} \varphi^{\mathrm{GB}}\left(\frac{R W A_{t}-R W A}{R W A}\right), \\
r_{t}^{l, \mathrm{SME}, \mathrm{LB}}=\left(r_{t}^{m}+l b s_{t}\right) \times M U^{\mathrm{SME}}, \\
r_{t}^{l, \mathrm{BF}, \mathrm{LB}}=\left(r_{t}^{m}+l b s_{t}\right) \times M U^{\mathrm{BF}} \\
r_{t}^{d}=r_{t}^{m}+l b s_{t}-\varphi^{\mathrm{LB}} \frac{D_{t}-D}{D}
\end{gathered}
$$

where $M U^{\mathrm{SME}}$ and $M U^{\mathrm{BF}}$ denote mark-ups applied to loans to SMEs and large firms, respectively, and $l b s_{t}$ is the exogenous local banking shock. We incorporate local banking shocks directly into the optimality condition by imposing a country-specific wedge on the equilibrium interbank loan rates demanded by the global bank. These shocks are mean-zero and potentially correlated across countries and shift the respective loan supply schedules up. In particular, a positive local banking shock would result in local bank demanding higher interest rates from its borrowers, as its own cost of funds rises. Due to mark-ups, the effective spread for the firms rises and they cut on production, employment, investment and credit. The real effects of the local banking shocks are most pronounced among firms that are particularly dependent on credit from local banks, namely SMEs.

Households Households consume a bundle of tradeable and local non-tradeable goods, supply labor to firms, and receive dividends (profits) from the firms and banks they own. They maximize their lifetime utility given by:

$$
\max _{\left\{C_{t}, N_{t}, D_{t}\right\}_{t=0}^{\infty}} \mathbb{E}_{0}\left[\sum_{t=0}^{\infty} \beta^{t}\left(\frac{C_{t}^{1-\sigma}-1}{1-\sigma}-\Psi \frac{N_{t}^{1+\psi}}{1+\psi}\right)\right],
$$


where $\beta$ is the discount factor, $\sigma$ is the coefficient of risk aversion, $\psi$ is the inverse Frisch elasticity, and $\Psi$ is the weight of labor disutility. Total labor, supplied by the household, is denoted by $N_{t}$ and is immobile across country borders, while $C_{t}$ represents a CES aggregate of consumption of the tradeable and non-tradeable goods (produced by large firms and SMEs, respectively), given by:

$$
C_{t}=\left(\omega^{\frac{1}{\epsilon}} C_{t}^{\mathrm{BF} \frac{\epsilon-1}{\epsilon}}+(1-\omega)^{\frac{1}{\epsilon}} C_{t}^{\mathrm{SME}} \frac{\frac{\epsilon-1}{\epsilon}}{{ }^{\frac{\epsilon}{\epsilon-1}}}\right.
$$

where $\omega$ expresses the household's preference towards tradeable goods and therefore determines relative sizes of the two sectors, and $\epsilon$ denotes the elasticity of substitution between the two goods.

The household's flow budget constraint is given by

$$
P_{t} C_{t}+D_{t}=W_{t} N_{t}+D_{t-1}\left(1+r_{t-1}^{d}\right)+\operatorname{DIV}_{t}^{\mathrm{BF}}+\operatorname{DIV}_{t}^{\mathrm{SME}}+\Pi_{t-1}^{\mathrm{LB}}+\mu^{\mathrm{GB}} \Pi_{t-1}^{\mathrm{GB}},
$$

where $P_{t}$ is the aggregate consumer-price index, $D_{t}$ is the holding of household deposits earning net interest $r_{t}^{d}$, and $W_{t} N_{t}$ is the total wage received by the household.

An optimizing household responds to shocks to discount factor by adjusting its labor supply, with associated equilibrium impacts on employment, output, and wages. In order to dampen these effects such that the reactions to interest shocks matches the data, we introduce real wage rigidities in a reduced form as proposed by Blanchard and Galí (2007), as follows:

$$
\log \left(\frac{W_{t}}{P_{t}}\right)=\gamma \log \left(\frac{W_{t-1}}{P_{t-1}}\right)+(1-\gamma) \log M R S_{t}
$$

where $M R S_{t}$ is the implied marginal rate of substitution, arising from optimal choice of labor by the household; i.e., $M R S_{t}=\Psi N_{t}^{\psi} C_{t}^{\sigma}$, and $\gamma$ is the persistence parameter, which can be interpreted as an index of real rigidities. This rigidity in real wages prevents an overreaction of wages and employment and achieves an empirically consistent negative response of labor and output to an interest rate shock for a wide range of parameters.

Market clearing Local markets for non-tradeable (SME-produced) goods clear according to:

$$
Y_{t}^{\mathrm{SME}}=(1-\omega)\left(\frac{P_{t}^{\mathrm{SME}}}{P_{t}}\right)^{-\epsilon}\left(C_{t}+I_{t}+\Gamma_{t}\right)
$$

where $\Gamma_{t}$ is total net real costs present in the model, which therefore can be thought of as part of gross real investment. ${ }^{17}$

\footnotetext{
${ }^{17}$ In our model, $\Gamma_{t}$ is composed of implicit firm borrowing costs $\left(L_{t}^{\mathrm{SME}, \mathrm{GB}}+L_{t}^{\mathrm{SME}, \mathrm{LB}}-L_{t}^{\mathrm{SME}}\right)+$ $\left(L_{t}^{\mathrm{BF}, \mathrm{GB}}+L_{t}^{\mathrm{BF}, \mathrm{LB}}-L_{t}^{\mathrm{BF}}\right)$, and all (second-order) adjustment costs.
} 
The tradeable goods market clears according to:

$$
Y_{t}^{\mathrm{BF}}=\omega\left(\frac{P_{t}^{\mathrm{BF}}}{P_{t}}\right)^{-\epsilon}\left(C_{t}+I_{t}+\Gamma_{t}\right)+\frac{N X_{t}}{P_{t}^{\mathrm{BF}}}
$$

Total net exports to rest of the world (from both home and foreign countries) are given by $N X_{t}+N X_{t}^{*}=B_{t-1}\left(1+r_{t}^{b}\right)-B_{t}$.

Market clearing conditions for the factor markets are given by $K_{t}=K_{t}^{\mathrm{BF}}+K_{t}^{\mathrm{SME}}$, $I_{t}=I_{t}^{\mathrm{BF}}+I_{t}^{\mathrm{SME}}$ and $N_{t}=N_{t}^{\mathrm{BF}}+N_{t}^{\mathrm{SME}}$.

Definitions Aggregate real GDP in the model is given by

$$
Y_{t}=\frac{P_{t}^{\mathrm{BF}}}{P_{t}} Y_{t}^{\mathrm{BF}}+\frac{P_{t}^{\mathrm{SME}}}{P_{t}} Y_{t}^{\mathrm{SME}}
$$

The SME share in the economy is then

$$
\mathrm{SME}_{t}=\frac{P_{t}^{\mathrm{SME}} Y_{t}^{\mathrm{SME}}}{P_{t} Y_{t}}
$$

with $\mathrm{SME} \approx 1-\omega$ in the steady-state.

Domestic bank dependence is defined as the ratio of locally originated loans to total loans to private sector in the economy:

$$
\mathrm{DBD}=\frac{L^{\mathrm{LB}}}{L^{\mathrm{LB}}+L^{\mathrm{GB}}}
$$

\section{Mapping the model to the data}

Calibration We normalize the size of GDP for each "home" economy to 1 and calibrate the baseline model at the quarterly frequency using parameter values displayed in Table 3. And because the "foreign" country represents "the rest of the EMU," we normalize its GDP to 10 ; i.e., the number of countries in the sample minus one. We additionally calibrate steadystate SME shares and domestic bank dependence for 11 countries in our sample as shown in Table 4. The model is then solved by log-linearizing around the deterministic steady-state.

The model counterpart of the global banking shock in our regressions, $\Delta \mathrm{GBS}_{t}$, is constructed as follows. We first simulate the model for all 11 countries in our sample to obtain artificial data on cross-border bank-to-bank lending $M_{t}$ and cross-border real sector lending $L_{t}^{\mathrm{GB}}$ (both for the "home" country). Given this data, we proceed in the same fashion as in the empirical section by calculating (the negative of) the difference between growth rates of aggregate cross-border lending to banks and cross-border lending to firms (where $c$ indexes 
the country):

$$
\Delta \mathrm{GBS}_{t}=-\left[\Delta \log \left(\sum_{c=1}^{11} M_{t}^{c}\right)-\Delta \log \left(\sum_{c=1}^{11} L_{t}^{\mathrm{GB}, c}\right)\right]
$$

Some of the parameters have been calibrated to standard values common in the literature. Households' discount factor $\beta$ is set to 0.99 , to match the steady-state quarterly net deposit rate of $1 \%$. The household's coefficient of relative risk aversion $\sigma$ is one, such that its instantaneous utility function is logarithmic with respect to the consumption bundle. The inverse of the Frisch elasticity $\psi$ in the utility function is set to 2, while the scale parameter $\Psi$ is determined by the steady-state restrictions. We assume a Cobb-Douglas specification for the consumption aggregate by setting the elasticity of substitution between tradeable and non-tradeable goods in consumption $(\epsilon)$ to 1 . The household preference parameter $\omega$ is then implicitly pinned down by the share of SMEs in a given economy.

The production functions of large and small firms are Cobb-Douglas with the capital intensity parameter $\alpha^{s}$ equal to 0.35 for each firm, which corresponds to a long-term share of capital in production in advanced economies. We set the capital depreciation parameter $\delta$ to 0.025 , and the investment adjustment cost parameter $\varphi^{I}$ to 2 . The index of real wage rigidities, $\gamma$, is set to 0.85 in order to match the business cycle moments for hours worked and is consistent with Blanchard and Galí (2007). We choose mark-ups of 3.5 and 2.5 for the loans extended to small and large firms, respectively. These values are in line with the calibration in Gerali et al. (2010), who use the value of 3.12, while we choose a larger markup for loans to small firms than for loans to large firms.

As to the risk-weights of the global bank, we assume that the regulator chooses higher risk weights for credit extended to the real sector than for interbank loans. Because claims on corporations are associated with risk weights ranging from $20 \%$ for firms with AAA to AA- ratings to $100 \%$ for unrated firms or those with low rating (BBB+ to $\mathrm{BB}-$ ), to $150 \%$ for firms with ratings below BB-, and depend on a range of additional criteria, including the quality of collateral, we assume that an average loan to a big firm receives the same weight attached to it as a loan to a small firm, equal to $75 \%$. This value is applied to loans to small businesses within regulatory retail portfolios in Basel II rules, and at the same time lies in the middle field within range of applied weights to rated and unrated corporations as described above. For bank-to-bank credit, we choose the weight 35\%, which is a simple average of weights applied to loans to banks with AAA to AA- ratings (20\%) and those with A+ to Aratings (50\%), and at the same time is used to weight claims secured by residential property, which was a common way of obtaining interbank liquidity through repo agreements prior to the crisis.

The next step in our calibration is choosing values for adjustment cost parameters for local and global banks. The first $\left(\varphi^{\mathrm{LB}}\right)$ is set to 0.01 , which allows us to match the con- 
sumption moments to the data. It also prevents perfect substitutability of interbank loans for deposits, especially in times of global downturns. As the cost is proportional to the percentage deviation of deposits from the steady-state, we choose the same steady-state value for deposits (relative to GDP) for all countries, at the value of 0.2 . We set the second adjustment cost parameter $\left(\varphi^{\mathrm{GB}}\right)$ to the value of 2 , such that the degree of substitutability between global bank real sector and interbank loans is high enough to manifest itself in a significantly higher contemporaneous drop of interbank loans in the crisis as a consequence of a negative banking shock.

We set the value for the elasticity of substitution between loans from local and global banks of firms $(\nu)$ to 0.5 , implying that firms treat these loans as complements, but still allow for imperfect correlation between them. This choice is consistent with our interpretation of firms borrowing technology as arising from hold-up problems due to relationship lending.

The corresponding CES preference parameters $\tau^{\mathrm{SME}}$ and $\tau^{\mathrm{BF}}$ are chosen to exactly match the model-implied DBD parameter to that obtained from the data, given the countryspecific SME shares. In particular, the following approximation holds in the steady state: $\mathrm{DBD} \approx \mathrm{SME} \times\left(1-\tau^{\mathrm{SME}}\right)+(1-\mathrm{SME}) \times\left(1-\tau^{\mathrm{BF}}\right) \cdot{ }^{18}$ Because we lack sectoral data allowing us to calibrate sectoral parameters $\tau$ directly, we assume that the domestic bank dependence of high-SME sectors in every country is a constant multiplier on the domestic bank dependence of the low-SME sectors. In particular, assuming $\left(1-\tau^{\mathrm{SME}}\right)=1.5 \times\left(1-\tau^{\mathrm{BF}}\right)$, allows us to calibrate sectoral local bank dependencies for every country in the range of $(0,1) \cdot{ }^{19}$

Forcing variables There are three major sources of shocks in our setup: shocks to total factor productivity (both high and low SME sectors), shocks to local banks, and shocks to the global bank. The TFP processes for any country $c$ (one for each sector $s$ ) are given by the following equations. For a home country (representing the simulation country $c$ ):

$$
\log \theta_{t}^{s}=\rho^{\theta} \log \theta_{t-1}^{s}-\sigma^{s}\left(\frac{\rho^{\dagger}}{\alpha^{\dagger}} \eta_{t}^{s, \dagger}+\sqrt{1-\left(\frac{\rho^{\dagger}}{\alpha^{\dagger}}\right)^{2}} \eta_{t}^{s}\right),
$$

and for a foreign country (representing "rest-of-EMU”):

$$
\log \theta_{t}^{s *}=\rho^{\theta} \log \theta_{t-1}^{s *}-\alpha^{\dagger} \sigma^{s} \eta_{t}^{s, \dagger}
$$

Similarly, the local banking shocks for both countries are as follows. For a home country

\footnotetext{
${ }^{18} \mathrm{DBD}=\frac{{ }^{\mathrm{LB}}}{L^{\mathrm{LB}}+L_{\mathrm{GB}}}=\frac{L^{\mathrm{SME}}}{L^{\mathrm{LB}}+L_{\mathrm{GB}}} \times \frac{{ }^{\mathrm{LB}, \mathrm{SME}}}{L^{\mathrm{SME}}}+\frac{L^{\mathrm{BF}}}{L^{\mathrm{LB}}+L_{\mathrm{GB}}} \times \frac{L^{\mathrm{LB}, \mathrm{BF}}}{L^{\mathrm{BF}}} \approx \mathrm{SME} \times\left(1-\tau^{\mathrm{SME}}\right)+$ $(1-\mathrm{SME}) \times\left(1-\tau^{\mathrm{BF}}\right)$.

${ }^{19}$ A potential alternative calibration assuming a constant value of domestic bank dependence for one of the sectors across all countries would need infeasible values outside the range of $(0,1)$ for at least one country in order to match the data.
} 
(representing the simulation country $c$ ):

$$
l b s_{t}=\rho^{l b s} l b s_{t-1}+\sigma^{l b s}\left(\frac{\rho^{\dagger}}{\alpha^{\dagger}} \eta_{t}^{l b s, \dagger}+\sqrt{1-\left(\frac{\rho^{\dagger}}{\alpha^{\dagger}}\right)^{2}} \eta_{t}^{l b s}\right),
$$

and for a foreign country (representing "rest-of-EMU"):

$$
l b s_{t}^{*}=\rho^{l b s} l b s_{t-1}^{*}+\alpha^{\dagger} \sigma^{l b s} \eta_{t}^{l b s, \dagger} .
$$

The stochastic process for the global banking shock has the same realization for every country and is given by

$$
\log B_{t}=\left(1-\rho^{g b s}\right) \log B+\rho^{g b s} \log B_{t-1}-\sigma^{g b s} \eta_{t}^{g b s}
$$

In the setup above, $\eta_{t}^{s}, \eta_{t}^{s, \dagger}, \eta_{t}^{l b s}, \eta_{t}^{l b s, \dagger}, \eta_{t}^{g b s} \stackrel{i . i . d .}{\sim} \mathcal{N}(0,1)$, and correspond, respectively, to idiosyncratic home-country sectoral TFP shocks, rest-of-the-EMU sectoral TFP shocks, idiosyncratic home-country local banking shocks, rest-of-the-EMU local banking shocks, and global (EMU-wide) banking shocks. All exogenous processes follow autoregressive dynamics with persistence parameters $\rho^{\theta}$ and $\rho^{g b s}$ equal to 0.95 , and $\rho^{l b s}$ equal to 0.80 . The cross-country correlation between shocks is $\rho^{\dagger}=0.25$. Given this correlation structure, the variance of the rest-of-the-EMU shocks are scaled by a parameter $\alpha^{\dagger}$, which also enters the stochastic processes of the home country. This parameter is defined for each simulation country $c$ as follows: $\alpha_{c}^{\dagger}=\left(\omega_{c}^{\prime} \Omega \omega_{c}\right)^{\frac{1}{2}}$, where $\omega_{c}=\operatorname{vec}\left(\frac{G D P_{j}}{\sum_{j \neq c} G D P_{j}}\right)$ and $\Omega=\left[\begin{array}{ccc}1 & \cdots & \rho^{\dagger} \\ \vdots & \ddots & \vdots \\ \rho^{\dagger} & \cdots & 1\end{array}\right]$.

The standard deviation of the global banking shock $\left(\sigma^{g b s}\right)$ is then set to 0.02 to match the volatility of the simulated $\Delta \mathrm{GBS}_{t}$ measure for a series of the standard normal shocks that allows to reconstruct the empirically observed series in the model, given the rest of the calibrated parameters. The volatility of the local banking shocks $\left(\sigma^{l b s}\right)$ is set to 0.0025 . It provides a comparable magnitude of the real effects of the local banking shocks, but at the same time does not bias the business cycle moments from the model-simulated data, that we briefly discuss below. Given these values and in order to match the standard deviation of the real GDP that we find in the data, the standard deviation of the TFP shocks $\sigma^{\theta}$ is set to 0.0125 .

Business cycle properties The business cycle properties of the calibrated model are given in Table 5. The first two columns present statistics for model simulations calibrated for Austria, which is typical for the countries in our sample in terms of SME and DBD, while the last two columns contain the respective data-counterparts, calculated for EMU-11 countries using data from Eurostat. For each variable in the table, we present the standard deviations 
relative to the standard deviation of GDP (except for net exports, which is a standard deviation of net exports-to-lagged-GDP ratio in percentage points) and correlation with domestic GDP of consumption, investment, employment, net exports and GDP (absolute standard deviation in percentage points). All model statistics are obtained from 1000 simulations with all shocks switched on and over 250 quarters, with the first 50 quarters dropped. All real data statistics are obtained from applying the HP-filter to variables in logarithms for the sample 1996Q1-2017Q4. To avoid that the HP-filter induces extreme values at either end of the sample and in order to focus on the pre-crisis period, we use the sample 1999Q1-2007Q4 to calculate the empirical moments.

The model matches almost all the data-statistics well in terms of standard deviations and correlations with GDP. The exceptions are investment and net exports-GDP ratio volatility, which are somewhat too high in the model for the Austria calibration.

\section{Quantitative results}

\subsection{Matching the empirical regressions}

We evaluate the ability of the model to fit the data by asking whether it can replicate the empirical findings in Tables 1 and 2, which motivated this study. To this end, we generate artificial data from the model and run the same regressions that we performed before, now on the simulated data. Because our actual data set comprises 11 countries, we calibrate the model for 11 countries, matching the pre-2008 average domestic bank dependence and 2008 SME share (see Table 4). We simulate the data for 60 quarters by calibrating global bank shocks $\left(\eta_{t}^{g b s}\right)$ to closely match the observed dynamics of our empirical $\Delta$ GBS measure prior to and during the crisis. As with the real data, we calculate annual growth rates of real per capita sectoral GVA by taking differences between quarter $t$ and $t-4$, so that $\Delta \log \mathrm{GVA}_{t}^{c, s}=$ $\log \mathrm{GVA}_{t}^{c, s}-\log \mathrm{GVA}_{t-4}^{c, s}$.

Table 6 presents two sets of regression results corresponding to our main empirical specification (4) (summarized in Table 2), and obtained from 10000 realizations of the scenarios described above. The output of the panel transmission regression on country-sector level, in which the dependent variable corresponds to sectoral value added growth, are presented in column (1). Further, column (2) replicates the before-after (cross-sectional) analysis, in which the dependent variable is the change of average sectoral output growth between the pre-2008 and the post-2008 periods. We demean all variables cross-sectionally (except for the sector indicator variable $\mathrm{SME}^{c, s}$ ) and include country-sector and time-sector fixed effects in the regression in column (1), and sector fixed effects in the regression in column (2). For each simulation we run the regressions, save the estimated coefficients, and use their distribution to construct the reported regression coefficients and $t$-statistics. In each simulation run, we draw new local banking shocks and global, country and sector-specific TFP shocks. 
In Table 6, the interaction term $\Delta \mathrm{GBS}_{t} \times \mathrm{SME}^{c, s} \times \mathrm{DBD}^{c}$, which captures any interaction between SME-share and domestic banking dependence, is negative and highly significant in the country-sector transmission regression in column (1). Moreover, we find a clear negative link between growth and domestic bank dependence in SME sectors across countries as supported by the results in column (2). The evidence from the before-after country-sector regression in column (2) is visualized in Figure 8 (cf. Figure 5): the slope is negative for SME firms and is much weaker for the sectors populated by large firms.

Quantitatively, our model-implied results from sectoral regressions of crisis transmission come close to the empirical findings in Table 2 (see column (4), which utilizes a dummy for high/low SME dependence). The interaction term $\left(\alpha_{1}\right)$ are highly significant and compare as -0.47 (model) against -0.43 (data). The same is true with regard to the before-after cross-sectional regression results. Although the coefficient on the interaction term in the empirical specifications in Table 2 (column (6) with high/low SME coding) (-0.10) is larger in absolute value than the coefficient implied by the model-simulated data $(-0.03)$, they compare well and consistently point in the same direction.

We complement our findings with results from local linear projection regressions (5) using model-simulated data and standardized $\Delta \mathrm{GBS}_{t}$ measure, separately for SME and nonSME sectors. These results are summarized in Figure 9. They closely mimic the local linear projections estimated from the data that we reported in Figure 6.

\subsection{Using the model to assess challenges to identification}

Our model simulations allow us to match the empirical regressions in Tables 1 and 2. Our setup so far assumed that the decline in cross-border bank-to-bank lending is driven by a shock to the balance sheet of global banks, which fits a narrative of the banking crises emanating from the United States. This raises the question to what extent other shock constellations could generate patterns similar to what we observe in the data.

For example, our interpretation of the banking shock as capturing credit supply to SMEs could be questioned, if there was a common (across countries) reduction in demand for loans that particularly affected countries with high domestic bank dependence and sectors with many SMEs. If that were the case, $\operatorname{cov}\left(\delta^{c, s}, \mathrm{DBD}^{c} \times \mathrm{SME}^{c, s}\right)$ might be non-zero. Because such a negative credit demand shock would also be correlated with $\Delta \mathrm{GBS}_{t}$, our identification assumption would be violated. In the same vein, one might conjecture that shocks to local banks that occurred simultaneously in the crisis countries could be driving our results.

To address this possibility, we simulate data from the model under three scenarios: first, a scenario with a global (i.e., common across countries) TFP shock in the SME sector. Second, a scenario with local correlated TFP shocks to the SME sectors in crisis countries and, third, a scenario with local correlated banking sector shocks in the crisis countries. In all three scenarios, the global banking sector shock is switched off and all other shocks for the non- 
crisis countries are assumed to be uncorrelated. Using the simulated data, we re-run our main regression (4) to assess how our coefficient of interest, $\alpha_{1}$, would be affected. ${ }^{20}$ Table 6 presents the results.

None of the counterfactuals delivers a negative significant coefficient to the interaction term $\Delta \mathrm{GBS}_{t} \times \mathrm{SME}^{c, s} \times \mathrm{DBD}^{c}$. If all countries experience simultaneous declines in the productivity of the high-SME sectors (counterfactual in column 1), the coefficient of interest is in fact positive. This result is due to the fact that while SME sectors are slightly more affected in high DBD countries (see row 1, column (3) in Figure 7, which plots the theoretical impulse responses to the shocks we discuss; see below), the B2B-over-B2N loans ratio increases. This effect seems to weaken (and even reverse) if instead, see column (2), only the set of crisis countries-Greece, Ireland, Italy, Portugal, and Spain-are hit by TFP shocks. The coefficient of the interaction term is negative, but close to zero and imprecisely estimated. Synchronized shocks to the local banking sector in the crisis countries, as shown in column (3) of Figure 7, induce a negative coefficient of a magnitude comparable to our baseline findings. This is consistent with the fact that the transmission of the global banking shock is similar to the transmission of the local banking shock in the model (confer columns (1) and (2) in Figure 7). However, because only a set of all countries is hit by the shocks and because the measure of the shock that we construct $-\Delta \mathrm{GBS}_{t}-$ is based on the growth rate of the average of bank flows of all countries in the sample, the global crisis proxy gets very noisy and leads to a high dispersion of the distribution of the simulated coefficients. In an empirical sample, this would lead us to reject the hypothesis that the global shock affects high SME sectors disproportionately in high DBD countries.

We conclude that, although all scenarios that we describe above could lead to a bias in the effect that we study, none of them delivers an alternative that fits the data. Only when we include a shock to the global banking sector do we find a large significant differential effect of the variable $\Delta \mathrm{GBS}_{t}$ on growth of sectoral value added.

Impulse responses: shock transmission To shed more light on the economic mechanisms that drive the results in Tables 6 and 7, Figure 7 displays impulse responses for small firm production, large firm production, bank-to-bank lending, and bank-to-bank over bankto-non-bank lending. The impulse responses are plotted for the model calibrated to the domestic bank dependence and small-firm share of Austria and Greece, respectively, as well as a counterfactual calibration for "Greece," where domestic banking dependence has been adjusted to the low level of Belgium.

The effect of a one standard deviation (2 percent) global banking shock-shock to interbank funds-is quite severe for a country with domestic banking dependence and smallfirm share at the level of Greece, for which it causes more than a 1.5 percent drop in the

\footnotetext{
${ }^{20}$ In order for the local shocks in the second and third scenario to cause the estimate of $\alpha_{1}$ to be significant, the shocks need to be correlated across crisis countries. Uncorrelated local shocks in all countries by construction are uncorrelated with $\Delta \mathrm{GBS}_{t}$ and will not affect our results.
} 
production of small firms on impact. The effect is smaller for a country like Austria and not very large for Greece if the domestic bank dependence had been similar to that of Belgium. Large firms, in the second row of figures, increase production but with little difference between the parametrizations. The third row shows the decline in bank-to-bank lending and the fourth row the decline in bank-to-bank lending over bank-to-real-sector lending. Both plummet on impact and remain low for many quarters ahead, with the magnitude of the decline between 5 and 8 percent.

The mechanics of the model is that a reduction in the size of the balance sheet of the global bank leads the bank to adjust its portfolio by investing relatively more in the real sector by providing more funds to firms and relatively less funds to local banks. This is because the latter carry a lower regulatory risk weight. Consequently, cross-border bank-to-bank credit falls more than bank-to-real sector credit, and local banks experience a shock to their liabilities making them reduce real sector lending. As a result, firms experience a more-thanproportional decrease in loan supply from local banks compared to global banks. Because SMEs are more dependent on local credit than big firms are, they adjust their production plans by reducing labor input and investment more than big firms. Large firms produce tradeable goods and the global banking shock induces a rise in domestic net exports and they benefit from the global bank shocks.

A local banking shock hurts small firms and this effect is larger if the country is dependent on domestic banks as seen for the Greece calibration in the middle column of figures. Large firms initially benefit, but after four quarter their production declines. Bank-to-bank lending declines and only slowly recovers. The impulse responses for a global TFP shock in SME sectors are plotted in column (3) of Figure 7, while the last column shows the transmission of the local TFP shocks in SME sectors. TFP shocks affect both large and small firms and "Austrian" and "Greek" large firms are similarly affected. However, small firms are hit slightly harder when the country is dependent on local banks even if bank-to-bank (over bank-to-non-bank) lending actually increases.

Overall, the impulse response functions clearly point to the mechanism that we want to draw attention to: the combination of domestic banking dependence and a large SMEsector leaves a country vulnerable to banking shocks, whether local or in the form of global liquidity shocks.

\section{Conclusion}

Small and medium-sized businesses have little access to outside capital, making their production vulnerable to banking shocks. The results in this paper show that sectors (and economies) with many small firms were less exposed to the recent crisis in the Eurozone in countries where they had access to credit from foreign banks rather than from purely domestic banks. We argue that banking integration in the Eurozone in the years before 2008 
was of the "wrong" kind in the sense that it was driven by lending from international banks to domestic banks, rather than by lending from international banks to the real economy. As we have shown empirically (using reduced-form regressions) and theoretically (in a DSGE model), this left local SMEs highly dependent on the domestic banking sector which in turn (due to short-term bank-to-bank lending) was vulnerable to the global banking sector shock.

Our findings have some interesting policy implications. Banking integration in Europe may require a "reset" that involves cross-border mergers between banks and consolidation of branch networks by retail banks across country-borders in the Eurozone, as happened in the United States after the state liberalization of state-level banking in the 1980s. In this way, international banks could operate genuine internal capital markets across national borders, allocating funds to bank-dependent SMEs in a recession. 


\section{References}

Adrian, Tobias, and Hyun Song Shin. 2014. "Procyclical Leverage and Value-at-Risk." The Review of Financial Studies, 27(2): 373-403.

Berger, Allen N., and Gregory F. Udell. 1995. "Relationship Lending and Lines of Credit in Small Firm Finance." The Journal of Business, 68(3): 351-381.

Bertrand, Marianne, Esther Duflo, and Sendhil Mullainathan. 2004. "How much should we trust Differences-in-Differences Estimates?" Quarterly Journal of Economics, 119 (1): 249-275.

Blanchard, Olivier, and Jordi Galí. 2007. "Real Wage Rigidities and the New Keynesian Model." Journal of Money, Credit and Banking, 39: 35-65.

Brunnermeier, Markus K., and Ricardo Reis. 2019. "Are Industrial-Country Consumption Risks Globally Diversified?” , (26229).

Bruno, Valentina, and Hyun Song Shin. 2015a. "Capital flows and the risk-taking channel of monetary policy." Journal of Monetary Economics, 71: 119-132.

Bruno, Valentina, and Hyun Song Shin. 2015b. "Cross-Border Banking and Global Liquidity." Review of Economic Studies, 82(2): 535-564.

Cetorelli, Nicola, and Linda S. Goldberg. 2012a. "Banking Globalization and Monetary Transmission." Journal of Finance, 67(5): 1811-1843.

Cetorelli, Nicola, and Linda S. Goldberg. 2012b. "Liquidity management of U.S. global banks: Internal capital markets in the great recession." Journal of International Economics, 88(2): 299-311.

Degryse, Hans, and Steven Ongena. 2005. "Distance, Lending Relationships, and Competition." The Journal of Finance, 60(1): 231-266.

Ferrando, Annalisa, Alexander Popov, and Gregory F. Udell. 2018. "Do SMEs Benefit from Unconventional Monetary Policy and How? Microevidence from the Eurozone." Journal of Money, Credit and Banking.

Ferrando, Annalisa, and Klaas Mulier. 2015. "Firms' Financing Constraints: Do Perceptions Match the Actual Situation?” The Economic and Social Review, 46(1): 87-117.

Gerali, Andrea, Stefano Neri, Luca Sessa, and Federico M. Signoretti. 2010. "Credit and Banking in a DSGE Model of the Euro Area." Journal of Money, Credit and Banking, 42: 107-141. 
Giannetti, Mariassunta, and Steven Ongena. 2007. "Financial Integration and Firm Performance: Evidence from Foreign Bank Entry in Emerging Markets*." Review of Finance, 13(2): 181-223.

Hale, Galina, and Maurice Obstfeld. 2016. "The Euro and the Geography of International Debt Flows." Journal of the European Economic Association, 14(1): 115-144.

Hale, Galina, Tumer Kapan, and Camelia Minoiu. forthcoming. "Shock Transmission Through Cross-Border Bank Lending: Credit and Real Effects." Review of Financial Studies.

Hoffmann, Mathias, and Toshihiro Okubo. 2017. “'By a Silken Thread': regional banking integration and credit reallocation during Japan's lost decade ." Manuscript, University of Zurich (https://mhoffmann.ocloud.de/index.php/s/0gRzCFnFLFlOa0I).

Imai, M., and S. Takarabe. 2011. "Bank Integration and Transmission of Financial Shocks: Evidence from Japan.” American Economic Journal: Macroeconomics, 3(1): 155-183.

International Monetary Fund. 2015. "Chapter 2: International Banking after the Crisis: Increasingly Local and Safer?”

Jordà, Òscar. 2005. "Estimation and Inference of Impulse Responses by Local Projections." American Economic Review, 95(1): 161-182.

Kalemli-Ozcan, Sebnem, Elias Papaioannou, and Fabrizio Perri. 2013. "Global banks and crisis transmission." Journal of International Economics, 89(2): 495 - 510.

Kalemli-Ozcan, Sebnem, Elias Papaioannou, and José-Luis Peydro. 2013. "Financial Regulation, Financial Globalization, and the Synchronization of Economic Activity." The Journal of Finance, 68(3): 1179-1228.

Kerl, Cornelia, and Friederike Niepmann. 2015. "What Determines the Composition of International Bank Flows?” IMF Economic Review, 63(4): 792-829.

Khwaja, Asim Ijaz, and Atif Mian. 2008. “Tracing the Impact of Bank Liquidity Shocks: Evidence from an Emerging Market." American Economic Review, 98(4): 1413-42.

Kollmann, Robert. 2013. "Global Banks, Financial Shocks, and International Business Cycles: Evidence from an Estimated Model." Journal of Money, Credit and Banking, 45(s2): 159-195.

Kollmann, Robert, Zeno Enders, and Gernot J. Müller. 2011. "Global Banking and International Business Cycles." European Economic Review, 55(3): 407 - 426. Special Issue: Advances in International Macroeconomics: Lessons from the Crisis. 
Martinez, Regina. 2015. "International Banking Flows and Credit Booms: Do Booms Go with the Flow?” Working Paper.

Melitz, Marc J. 2003. “The Impact of Trade on Intra-Industry Reallocations and Aggregate Industry Productivity." Econometrica, 71(6): 1695-1725.

Mian, Atif. 2006. "Distance Constraints: The Limits of Foreign Lending in Poor Economies.” The Journal of Finance, 61(3): 1465-1505.

Morgan, Donald P., Bertrand Rime, and Philip E. Strahan. 2004. "Bank Integration and State Business Cycles.” Quarterly Journal of Economics, 119 (4): 1555-85.

Neumeyer, Pablo A., and Fabrizio Perri. 2005. "Business Cycles in Emerging Economies: The Role of Interest Rates." Journal of Monetary Economics, 52(2): 345-380.

Peek, Joe, and Eric S. Rosengren. 1997. "The International Transmission of Financial Shocks: The Case of Japan.” The American Economic Review, 87(4): pp. 495-505.

Peek, Joe, and Eric S. Rosengren. 2000. "Collateral Damage: Effects of the Japanese Bank Crisis on Real Activity in the United States.” The American Economic Review, 90(1): 30-45.

Petersen, Mitchell A., and Raghuram G. Rajan. 1994. “The Benefits of Lending Relationships: Evidence from Small Business Data." The Journal of Finance, 49(1): 3-37.

Rajan, Raghuram G., and Luigi Zingales. 1998. "Financial Dependence and Growth." The American Economic Review, 88(3): 559-586.

Rey, Hélène. 2015. "Dilemma not Trilemma: The Global Financial Cycle and Monetary Policy Independence.” National Bureau of Economic Research Working Paper 21162.

Schmitt-Grohé, Stephanie, and Martín Uribe. 2003. "Closing Small Open Economy Models." Journal of International Economics, 61(1): 163-185.

Schnabel, Isabel, and Christian Seckinger. 2015. "Financial Fragmentation and Economic Growth in Europe.” GSME Discussion Paper Series.

Sharpe, Steven A. 1990. "Asymmetric Information, Bank Lending and Implicit Contracts: A Stylized Model of Customer Relationships." The Journal of Finance, 45(4): pp. 10691087.

Sørensen, Bent E., and Carolina Villegas-Sanchez. 2015. "Factor Movements: FDI." In Handbook of the Economics of European Integration. , ed. Harald Badinger and Volker Nitsch. Routledge. 
Table 1: Domestic Bank Dependence, SME shares and crisis transmission

\begin{tabular}{|c|c|c|c|c|}
\hline & \multicolumn{4}{|c|}{ Sector-country level } \\
\hline & (1) & $(2)$ & (3) & (4) \\
\hline & \multicolumn{4}{|c|}{ Growth in sectoral value added } \\
\hline$\Delta \mathrm{GBS}_{t} \times \mathrm{SME}^{\mathrm{s}} \times \mathrm{DBD}$ & $\begin{array}{c}-1.32^{* * *} \\
(-3.23)\end{array}$ & $\begin{array}{l}-1.24^{* * *} \\
(-3.04)\end{array}$ & $\begin{array}{l}-1.04^{* *} \\
(-2.13)\end{array}$ & $\begin{array}{c}-0.97^{* *} \\
(-2.08)\end{array}$ \\
\hline$\Delta \mathrm{GBS}_{t} \times \mathrm{SME}^{\mathrm{s}}$ & $\begin{array}{c}0.12 \\
(1.24)\end{array}$ & $\begin{array}{c}0.13 \\
(1.37)\end{array}$ & $\begin{array}{c}0.12 \\
(1.26)\end{array}$ & $\begin{array}{c}0.13 \\
(1.39)\end{array}$ \\
\hline$\Delta \mathrm{GBS}_{t} \times \mathrm{DBD}$ & $\begin{array}{c}-0.25 \\
(-1.04)\end{array}$ & $\begin{array}{c}-0.11 \\
(-0.53)\end{array}$ & $\begin{array}{c}0.02 \\
(0.16)\end{array}$ & $\begin{array}{l}0.15^{* *} \\
(2.51)\end{array}$ \\
\hline$\Delta \mathrm{GBS}_{t} \times \mathrm{CORE}$ & & $\begin{array}{c}0.10^{* * *} \\
(3.02)\end{array}$ & & $\begin{array}{c}0.09^{* * *} \\
(3.51)\end{array}$ \\
\hline$\Delta \mathrm{GBS}_{t} \times$ GREECE & & & $\begin{array}{c}-0.24^{* * *} \\
(-4.88)\end{array}$ & $\begin{array}{c}-0.23^{* * *} \\
(-4.92)\end{array}$ \\
\hline Observations & 4,224 & 4,224 & 4,224 & 4,224 \\
\hline Adjusted $\mathrm{R}^{2}$ & 0.27 & 0.28 & 0.28 & 0.28 \\
\hline
\end{tabular}

NOTES: The table presents estimates of our baseline specification:

$\Delta \log \mathrm{GVA}_{t}^{c, s}=\Delta \mathrm{GBS}_{t} \times\left[\alpha_{1} \mathrm{DBD}^{c} \times \mathrm{SME}^{c, s}+\alpha_{2} \mathrm{SME}^{c, s}+\alpha_{3} \mathrm{DBD}^{c}\right]+$ CONTROLS $+\tau_{t}+\mu^{c, s}+\varepsilon_{t}^{c, s}$.

Regressions include time and country-sector effects. Standard errors are clustered by country and time, $t$-statistics are in parentheses. Columns 2-4 include an interaction of the $\Delta \mathrm{GBS}_{t}$ indicator with a dummy for the core economies and/or for Greece. The sample includes 66 country-sectors, six in each of the 11 EMU countries Austria, Belgium, Finland, France, Germany, Greece, Ireland, Italy, the Netherlands, Portugal, and Spain. The core economies are Belgium, France, Germany, and the Netherlands. The sample period is 1997Q1-2013Q4. 


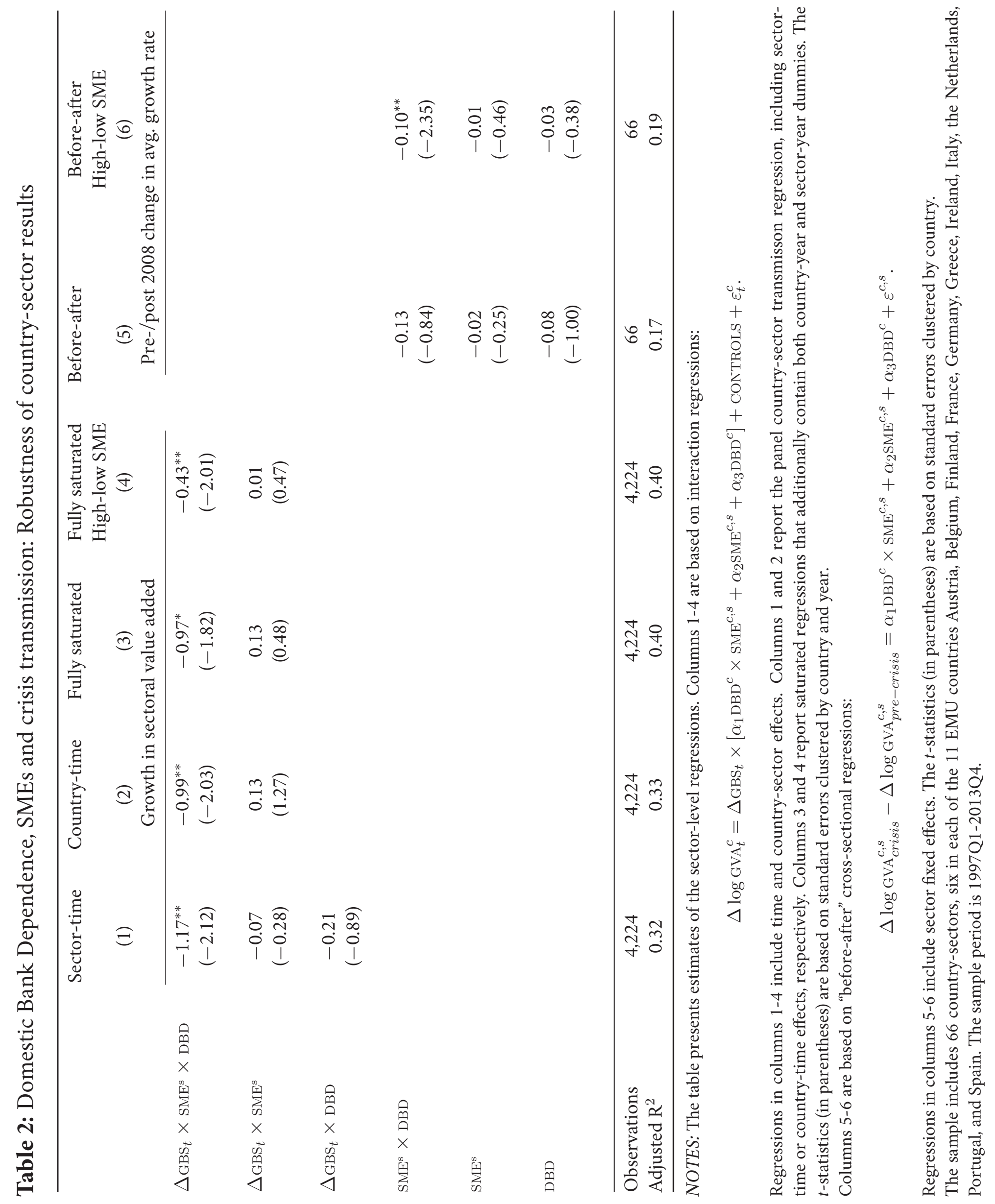


Table 3: Model calibration

\begin{tabular}{llc}
\hline Parameter & Description & Value \\
\hline$\beta$ & Households' discount factor & 0.99 \\
$\psi$ & Inverse of Frisch elasticity & 2 \\
$\sigma$ & Households' risk aversion & 1 \\
$\epsilon$ & Elasticity of substitution between tradeable and non-tradeable goods & 1 \\
$\gamma$ & Index of real wage rigidities & 0.80 \\
$\alpha^{B F}$ & Capital intensity in BFs' production function & 0.35 \\
$\alpha^{S M E}$ & Capital intensity in SMEs' production function & 0.35 \\
$\varphi^{I}$ & Investment adjustment cost parameter & 2 \\
$\delta$ & Capital depreciation & 0.025 \\
$\nu$ & Firms' elasticity of substitution between GB and LB loans & 0.5 \\
$M U^{B F}$ & Mark-up on BF's credit rates & 2.5 \\
$M U^{S M E}$ & Mark-up on SME's credit rates & 3.5 \\
$\varphi^{L B}$ & Local bank adjustment cost in deposits & 0.01 \\
$\varphi^{G B}$ & Global bank adjustment cost in risk-weighted assets & 2 \\
$D / G D P$ & Steady state ratio of deposits to GDP & 0.2 \\
$\gamma^{L}$ & Risk weight on credit to real sector & 0.75 \\
$\gamma^{M}$ & Risk weight on interbank credit & 0.35 \\
$\rho^{\theta}$ & TFP shocks autocorrelation coefficient & 0.95 \\
$\rho^{g b s}$ & Global banking shock autocorrelation coefficient & 0.95 \\
$\rho^{l b s}$ & Local banking shock autocorrelation coefficient & 0.80 \\
$\sigma^{\theta}$ & Standard deviation of TFP shocks & 0.0125 \\
$\sigma^{g b s}$ & Standard deviation of global banking shock & 0.02 \\
$\sigma^{l b s}$ & Standard deviation of local banking shock & 0.0025 \\
$\rho^{\dagger}$ & International correlation of TFP shocks & 0.25 \\
\hline & & \\
\hline$O T E S: A d d i$ &
\end{tabular}

NOTES: Additionally, we calibrate home and foreign nominal SME share and DBD parameters (see Table 4). These parameters implicitly determine the values of other model parameters $\omega, \tau$, and $\Psi$. 
Table 4: Calibration of SME and DBD for EMU-11 countries

\begin{tabular}{lll}
\hline & SME & DBD \\
\hline Austria & 0.60 & 0.68 \\
Belgium & 0.59 & 0.46 \\
Finland & 0.54 & 0.44 \\
France & 0.60 & 0.54 \\
Germany & 0.52 & 0.78 \\
Greece & 0.64 & 0.85 \\
Ireland & 0.54 & 0.62 \\
Italy & 0.71 & 0.73 \\
Netherlands & 0.64 & 0.51 \\
Portugal & 0.68 & 0.68 \\
Spain & 0.67 & 0.75 \\
\hline EMU & 0.61 & 0.67 \\
\hline
\end{tabular}

NOTES: The values for DBD are constructed as pre-2008 within-country averages, while the 2008 data are used to construct the values for SME.

Table 5: Business cycle properties of the model

\begin{tabular}{lcccc}
\hline & \multicolumn{2}{c}{ Austria } & \multicolumn{2}{c}{ Data } \\
& St.Dev. & Corr. & St.Dev. & Corr. \\
\hline GDP & $1.60^{*}$ & & $1.59^{*}$ & \\
Consumption & 0.65 & 0.69 & 0.64 & 0.74 \\
Investment & 4.96 & 0.65 & 2.85 & 0.82 \\
Employment & 0.58 & 0.79 & 0.62 & 0.75 \\
Net exports & 2.35 & -0.09 & 1.09 & -0.26 \\
\hline
\end{tabular}

NOTES: The table reports theoretical and empirical standard deviations ("St.Dev.") and correlations ("Corr.") of the variables. The theoretical moments are shown for Austria, which is the "representative" country in our sample. The empirical moments are averages across 11 countries in our sample: Austria, Belgium, Finland, France, Germany, Greece, Ireland, Italy, Netherlands, Portugal, and Spain. All statistics are obtained from applying the HP-filter to variables in logarithms for the sample 1996Q1-2017Q4. To avoid HP-filter induced beginning-of-sample extreme values and to focus on the pre-crisis period, we use the sample 1999Q1-2007Q4 to calculate the empirical moments. Standard deviations are the ratio of the standard deviation to the standard deviation of GDP (except for net exports, which is the standard deviation of net exports-to-GDP ratio in percentage points). All model statistics are obtained from 1000 simulations with all shocks switched on, over 250 quarters, with the first 50 quarters dropped. 
Table 6: Domestic bank dependence, SME-sectors, and crisis transmission: Baseline model simulation results

(1)

Growth in sectoral value added Pre-/post crisis change in avg. growth rate

\begin{tabular}{lcc}
\hline & $-0.467^{* * *}$ & \\
$\mathrm{SME}^{\mathrm{s}} \times \mathrm{DBD} \times \Delta \mathrm{GBS}$ & $(-2.713)$ & \\
$\mathrm{DBD} \times \Delta \mathrm{GBS}$ & 0.082 & -0.033 \\
& $(0.769)$ & $(-0.919)$ \\
$\mathrm{SME}^{\mathrm{s}} \times \mathrm{DBD}$ & & -0.003 \\
& & $(-0.106)$ \\
$\mathrm{DBD}$ & 1408 & 22 \\
\hline $\mathrm{N}$ & & 22 \\
\hline
\end{tabular}

NOTES: The table presents estimates of our baseline specification in column (1) and the crosssectional before-after analysis in column (2).

In column (1), we estimate the following specification:

$$
\Delta \log \mathrm{GVA}_{t}^{c, s}=\Delta \mathrm{GBS}_{t} \times\left[\alpha_{1} \mathrm{DBD}^{c} \times \mathrm{SME}^{c, s}+\alpha_{2} \mathrm{DBD}^{c}\right]+\mu^{t, s}+\mu^{c, s}+\varepsilon_{t}^{c, s} .
$$

This regression includes time-sector and country-sector fixed effects. The term $\Delta \mathrm{GBS}_{t} \times \mathrm{SME}^{c, s}$ is absorbed by time-sector fixed effects, since in the model $\mathrm{SME}^{c, s}$ only varies across sectors, but not across countries.

In column (2), we estimate the following specification:

$$
\Delta \log \mathrm{GVA}_{c r i s i s}^{c, s}-\Delta \log \mathrm{GVA}_{\text {pre-crisis }}^{c, s}=\alpha_{1} \mathrm{DBD}^{c} \times \mathrm{SME}^{c, s}+\alpha_{2} \mathrm{DBD}^{c}+\mu^{s}+\varepsilon^{c, s} .
$$

This regression includes sector fixed effects. The term $\mathrm{SME}^{c, s}$ is absorbed by sector fixed effects, since in the model $\mathrm{SME}^{c, s}$ only varies across sectors, but not across countries.

Estimated coefficients and $t$-stats (in parentheses) are derived from sample means and standard deviations of the simulated regression coefficients. In particular, for every of 10000 simulations, we run the regressions, save the estimated coefficients, and use their distribution to construct the reported values. The model has been calibrated for 11 EMU countries. We obtained time series over 60 quarters for each of the simulated variables. All variables have been cross-sectionally demeaned. Statistical significance at $1 / 5 / 10$ percent level is denoted by ${ }^{* * *},{ }^{* *}$, and ${ }^{*}$, respectively. 


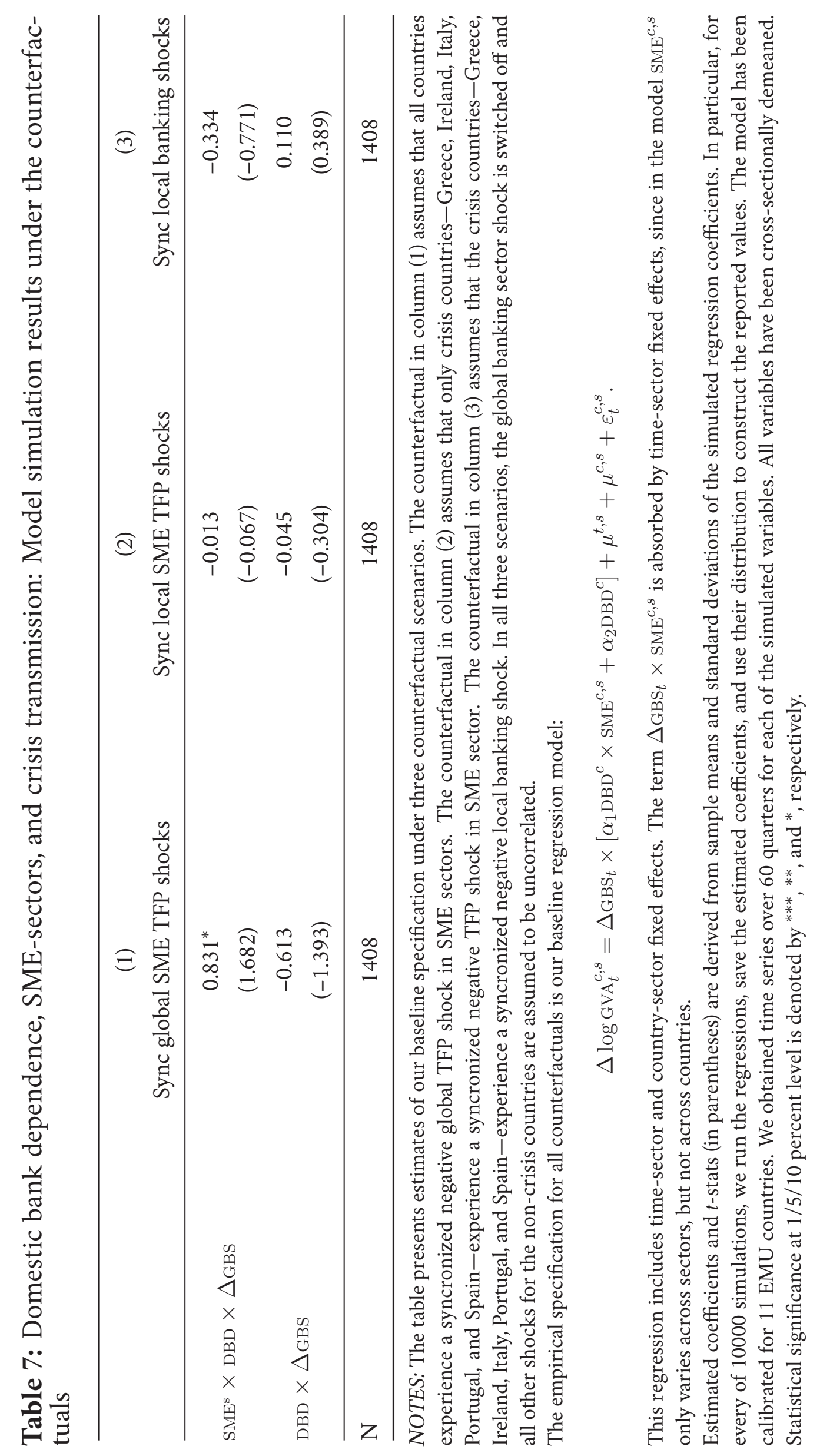


Figure 1: Cross-border bank lending in selected Eurozone countries

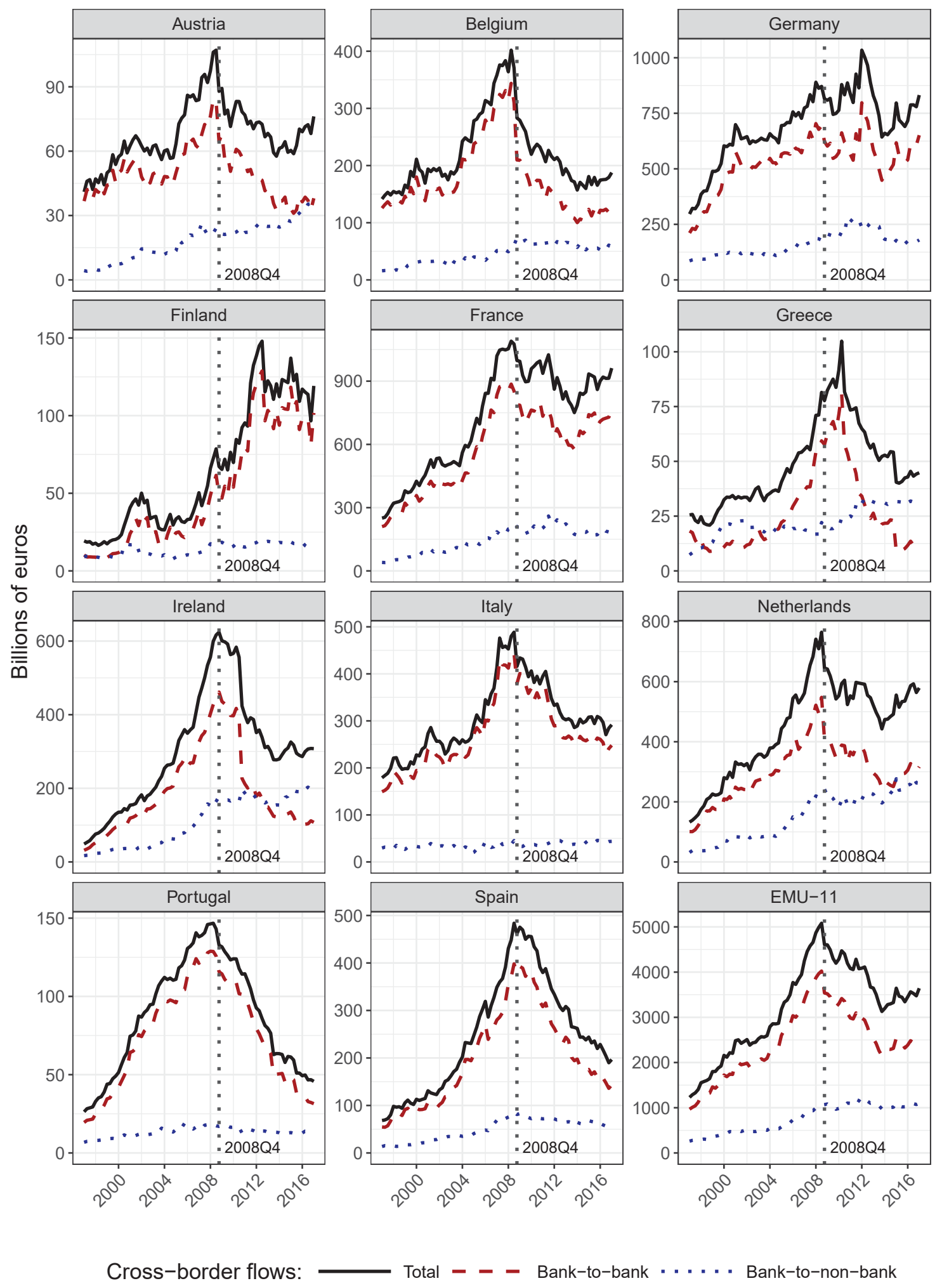

NOTES: The figure plots cross-border lending by foreign banks to each country. The last panel plots aggregate EMU-11 cross-border flows. The black solid line shows total lending, the red dashed line shows lending by foreign banks to domestic banks, and the blue dotted line shows lending by foreign banks to the domestic non-bank sector (including governments). The source is BIS locational banking statistics database. 


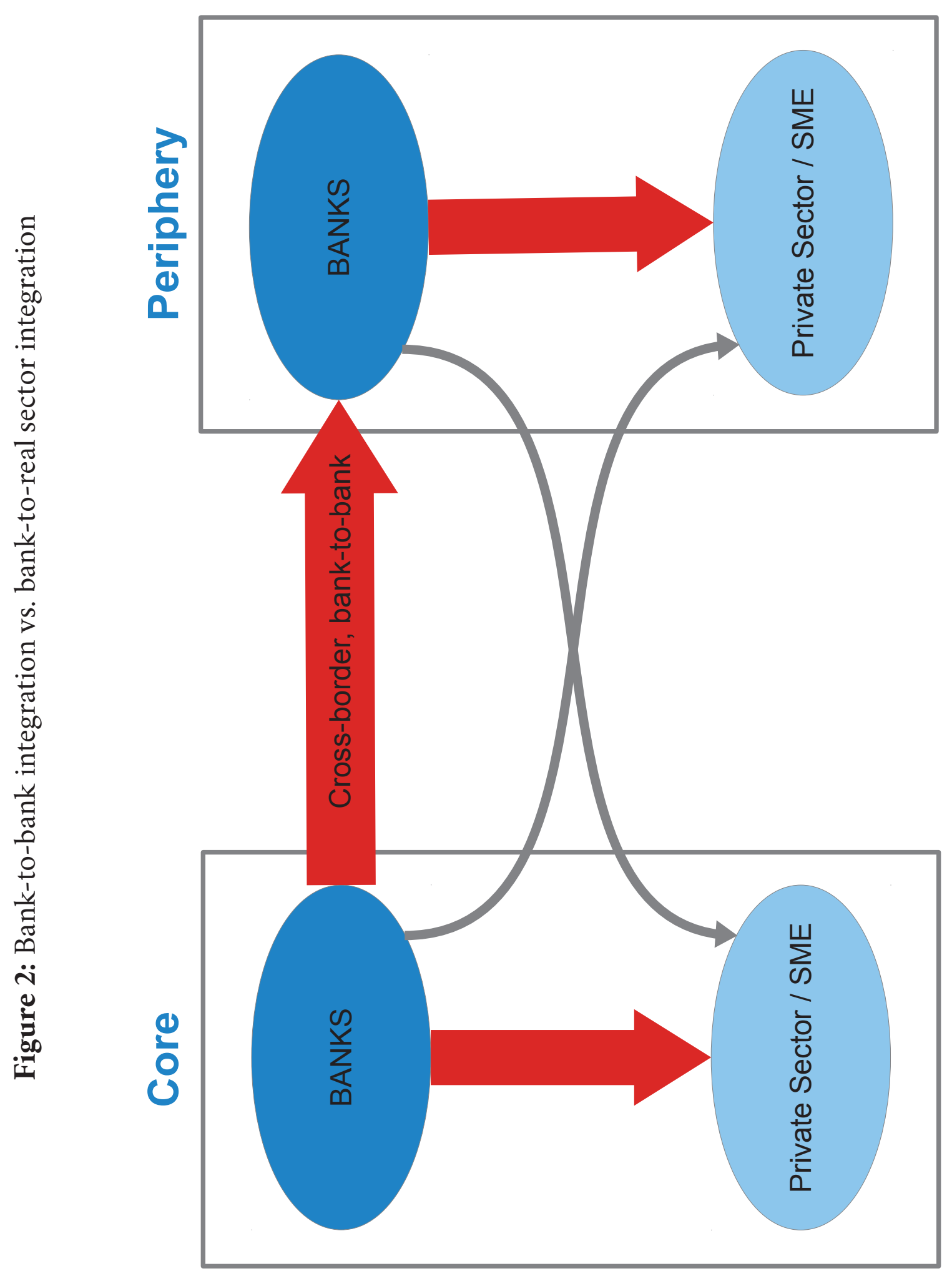

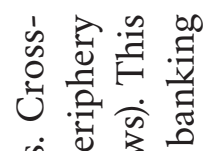

离范

氙

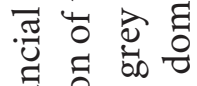

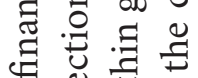

栗

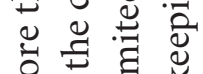

品

क त

एक

㲾苛

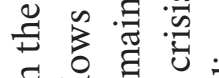

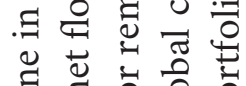

范苛

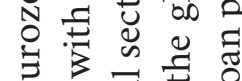

凷考

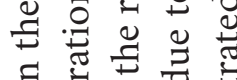

ज 50 ह

.ี

픈

कo 해을

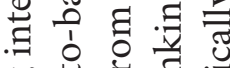

bo

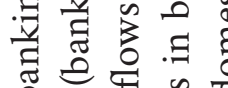

क्ष क्ष

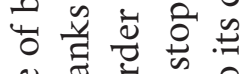

둥

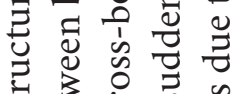

क

过

巡苛产

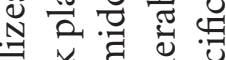

ज 능 ह

월 के

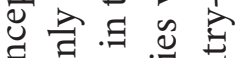

ชิ

¿

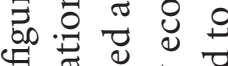

( )

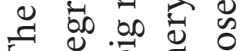

is.

出离 


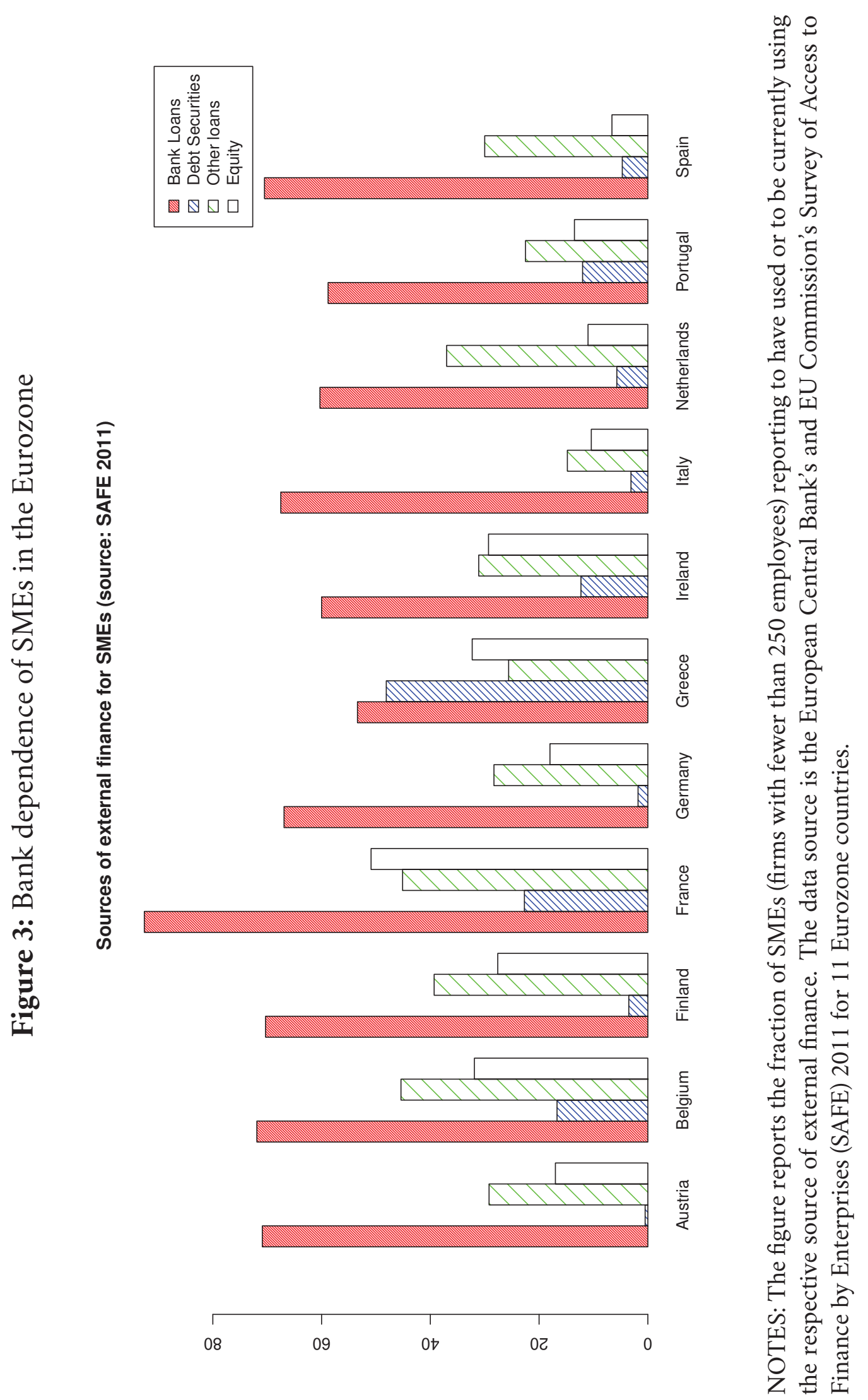




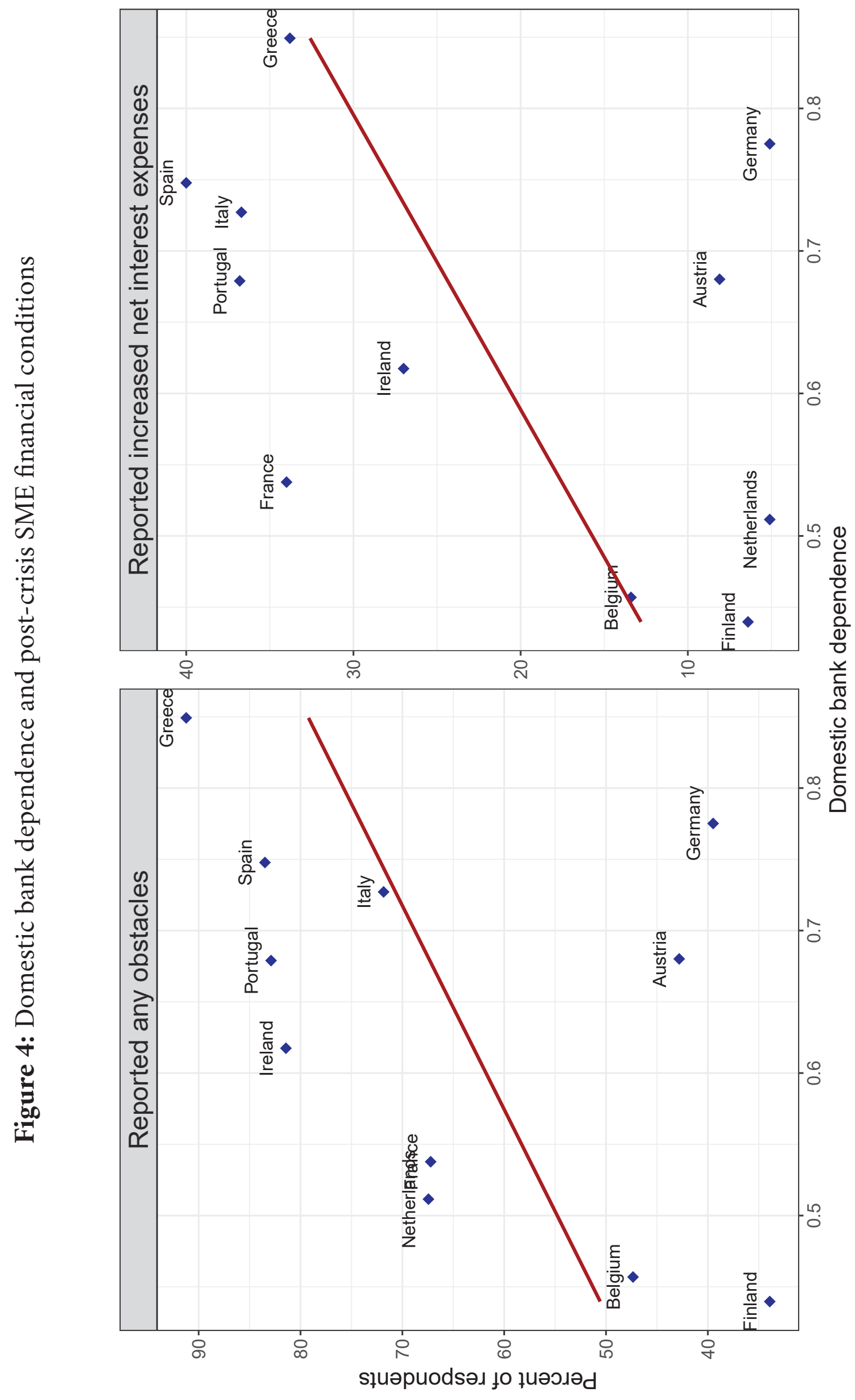

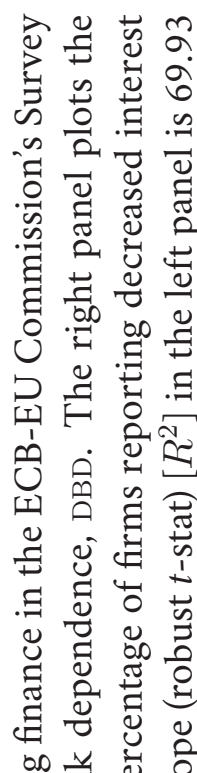

o $\frac{x}{3}$ 这

.

월

$\exists$ 寻

卷

焉范范

芯芯苍

总志芯芯

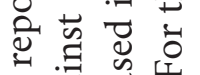

䒿

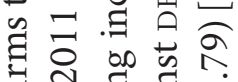

Nㅡㄹ

प्ञ

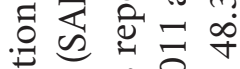

Чै 气 규.?

出氙贸

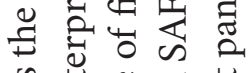

䒕苀些. 亖

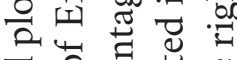

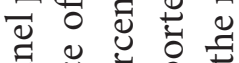

ฉ̃

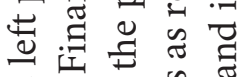

E

is

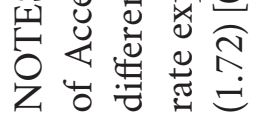


Figure 5: Post-2008 sector-level growth and domestic bank dependence: Sectors with low vs. high SME shares

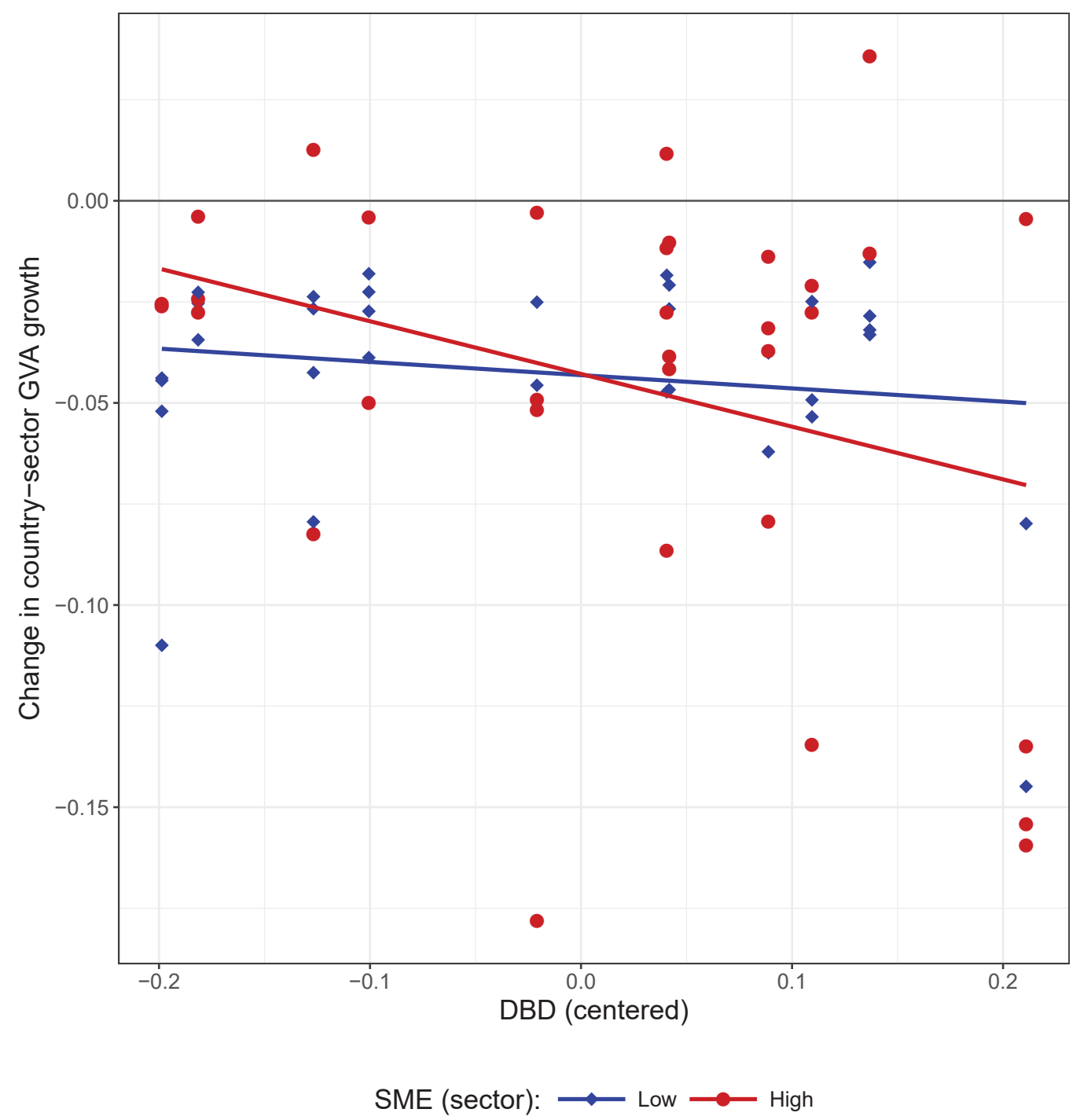

NOTES: The graph plots the change in output from pre-2008 to post-2008 average growth rates at the country-sector level against the average pre-2008 level of domestic bank dependence in each country. Blue (red) diamonds (circles) indicate country-sectors with below (above) median SME shares. The blue, dashed (red, solid) lines indicate the regression relationship between growth and domestic bank dependence for the sample of blue (red) diamonds (circles). The observation period is 1997Q1-2013Q4 for the 11 EMU countries Austria, Belgium, Finland, France, Germany, Greece, Ireland, Italy, the Netherlands, Portugal, and Spain. 
Figure 6: Global banking shock and domestic bank dependence in sectors with low vs. high SME shares: Local linear projections

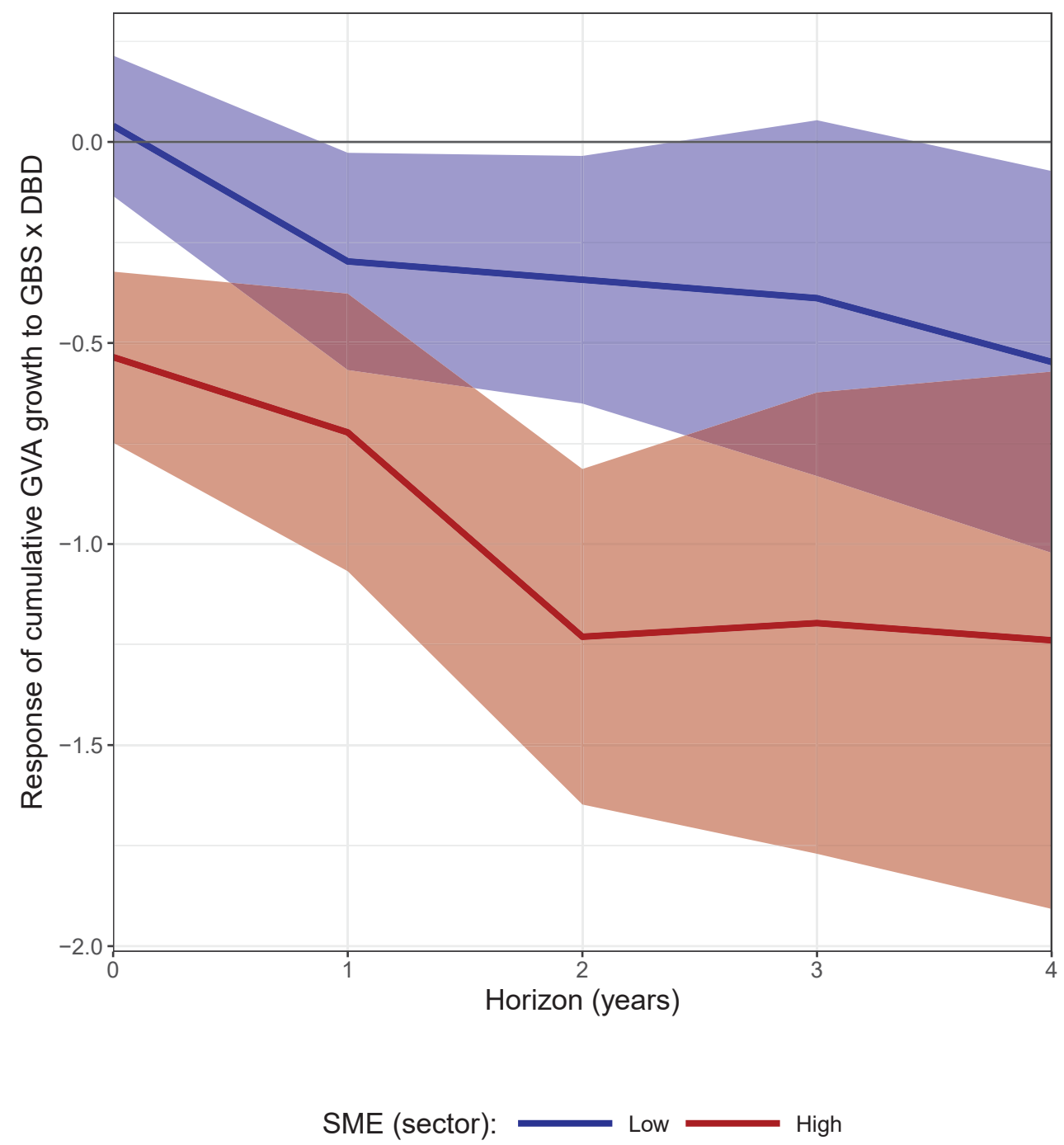

NOTES: The graph plots the cumulative effect of the interaction terms $\mathrm{CRISIS}_{t} \times \mathrm{DBD}^{c}$ from local linear projection regressions, separately for high-SME sectors (red) and low-SME sectors (blue). Different horizons (zero to four years) are on the x-axis, and the coefficients $\alpha_{h}$ is on the y-axis.. Colored shaded areas correspond to the respective $90 \%$ confidence bands. The observation period is 1997Q1-2013Q4 for the 11 EMU countries Austria, Belgium, Finland, France, Germany, Greece, Ireland, Italy, the Netherlands, Portugal, and Spain. 
Figure 7: Model impulse responses to a global banking shock, a local banking shock, a global SME TFP shock and a local SME TFP shock

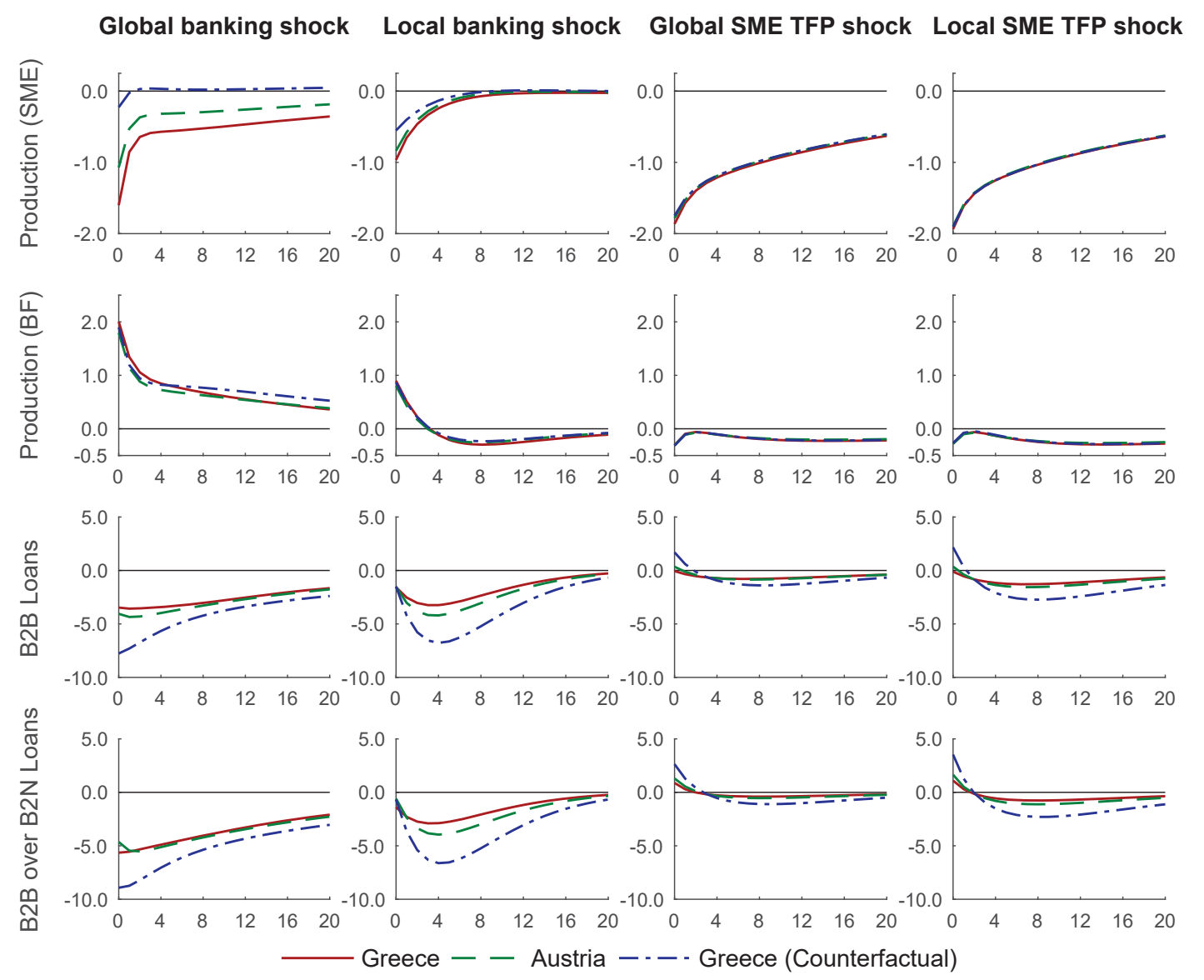

NOTES: The graph plots the model impulse response functions of SME production, big firms production, bank-to-bank loans and B2B-to-B2N ratio (rows) for "Greece" (red solid lines), "Austria" (blue dashed lines) and "Greece (Counterfactual)" (green dot-dashed lines) to a one standard deviation global banking shock, local banking shock, global SME TFP shock and local SME TFP shock (columns). "Greece" and "Austria" impulse responses are generated from models simulated using parameter values from Table 4. "Greece (Counterfactual)" illustrates the counterfactual scenario for Greece, in which we calibrate the model for Greece (e.g., the SME share), but set the DBD parameter to its value for Belgium. All impulse responses are percentage deviations from steady state. Number of quarters following the shock is on the $\mathrm{x}$-axis. 
Figure 8: Post-2008 sector-level growth and domestic bank dependence in sectors with low vs. high SME shares: Model simulation results

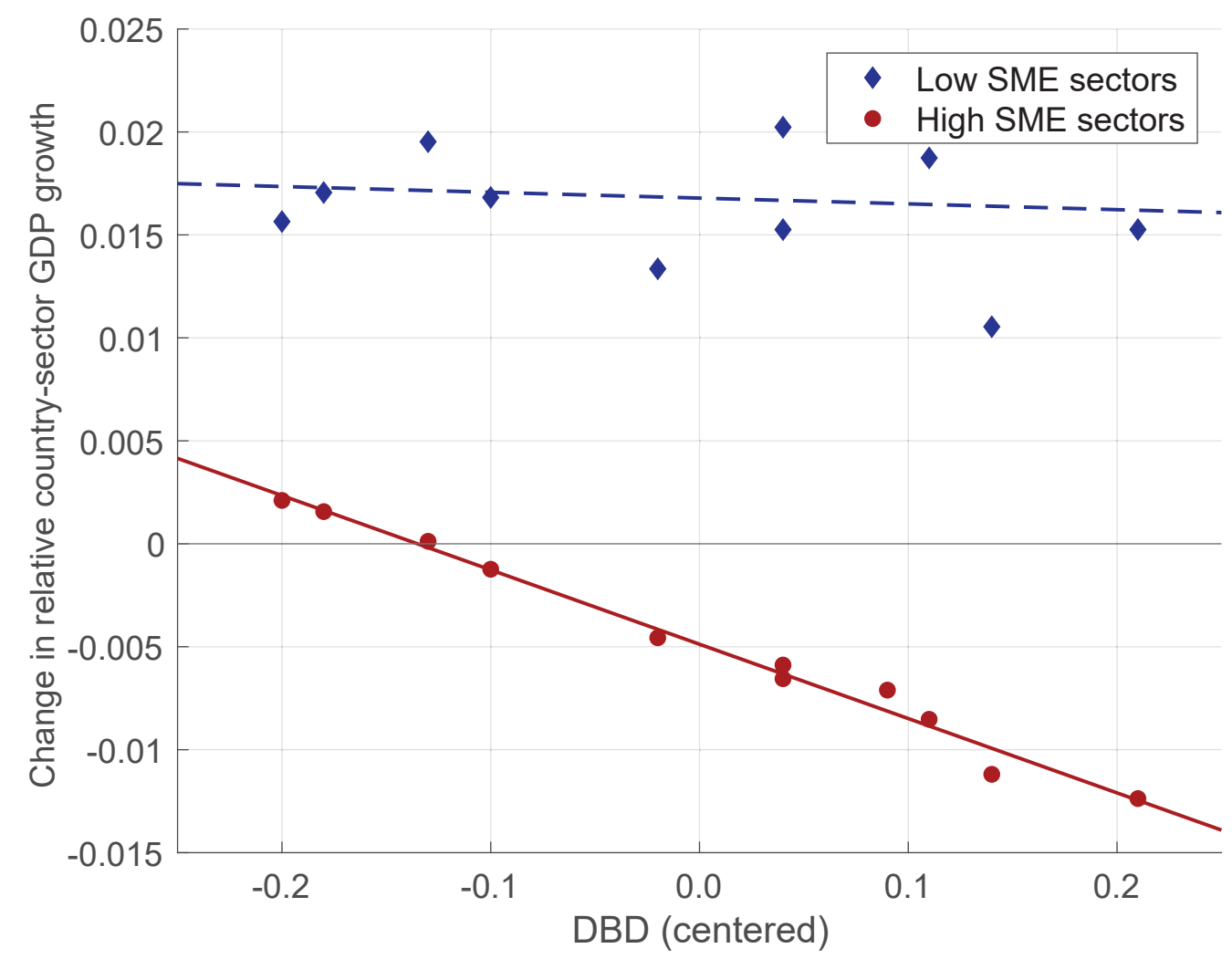

NOTES: The graph plots the change in output from "pre-crisis" to "crisis" average growth rates at the country-sector level against the steady-state level of domestic bank dependence in each country. Blue (red) diamonds (circles) indicate BF (SME) sectors. The blue, dashed (red, solid) lines indicate the regression relationship between growth and domestic bank dependence for the sample of blue (red) diamonds (circles). Data and line slopes are obtained from 1000 model simulations, calibrated for 11 EMU countries and run over 60 quarters, including 20 quarters of the "crisis" period. 
Figure 9: Global banking shock and domestic bank dependence in sectors with low vs. high SME shares: Model simulation results using local linear projections

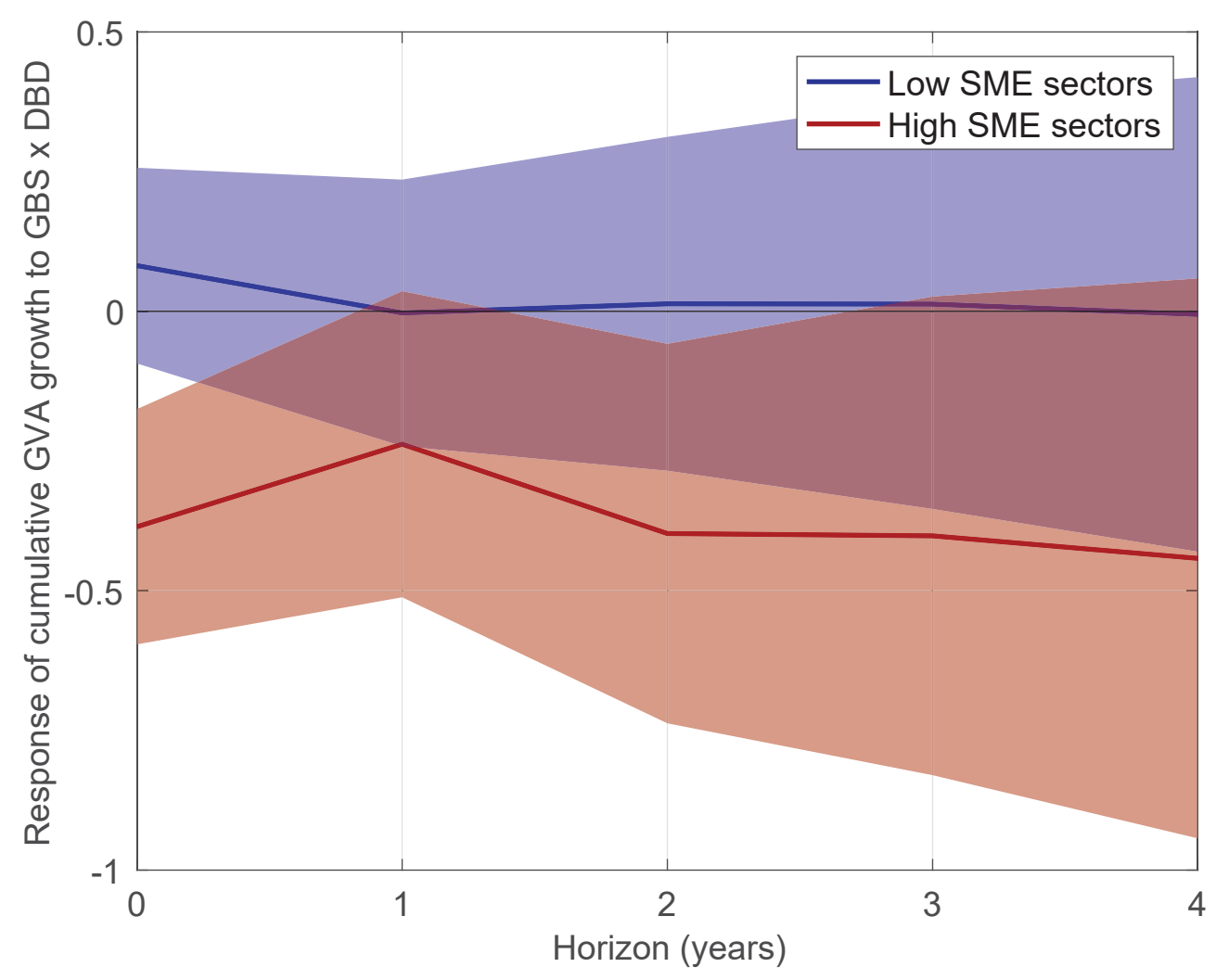

NOTES: The graph plots the cumulative effect of the interaction terms $\Delta \mathrm{GBS}_{t} \times \mathrm{DBD}^{c}$ from local linear projection regressions on model-simulated data, separately for SME sectors (red) and non-SME sectors (blue). Different horizons (zero to four years) are on the x-axis, and the coefficients $\alpha_{h}$ is on the y-axis. Colored shaded areas correspond to the respective $90 \%$ confidence bands, calculated from the distribution of the estimated coefficients across model simulations. The impulse responses are obtained from 1000 model simulations, calibrated for 11 EMU countries and run over 60 quarters, including 20 quarters of the "crisis" period. 


\section{A Model equations (for publication as additional web ma- terial only)}

\section{Households}

Households objective:

$$
\max _{\left\{C_{t}, N_{t}, D_{t}\right\}_{t=0}^{\infty}} \mathbb{E}_{0}\left[\sum_{t=0}^{\infty} \beta^{t}\left(\frac{C_{t}^{1-\sigma}-1}{1-\sigma}-\Psi \frac{N_{t}^{1+\psi}}{1+\psi}\right)\right]
$$

(s.t.) Intertemporal budget constraint

$$
P_{t} C_{t}+D_{t}=W_{t} N_{t}+D_{t-1}\left(1+r_{t-1}^{d}\right)+\operatorname{DIV}_{t}^{\mathrm{BF}}+\operatorname{DIV}_{t}^{\mathrm{SME}}+\Pi_{t-1}^{\mathrm{LB}}+\mu^{\mathrm{GB}} \Pi_{t-1}^{\mathrm{GB}}
$$

$\operatorname{SDF}\left(\right.$ FOC w.r.t. $C_{t}$ ):

$$
\Lambda_{t: t+1}=\mathbb{E}_{t}\left[\beta \frac{P_{t}}{P_{t+1}}\left(\frac{C_{t+1}}{C_{t}}\right)^{-\sigma}\right]
$$

FOC w.r.t. $N_{t}$ including real wage rigidity (Blanchard \& Gali (JMBC 2007)):

$$
\log \left(\frac{W_{t}}{P_{t}}\right)=\gamma \log \left(\frac{W_{t-1}}{P_{t-1}}\right)+(1-\gamma) \log \left(\Psi N_{t}{ }^{\psi} C_{t}{ }^{\sigma}\right)
$$

FOC w.r.t. $D_{t}$ :

$$
\mathbb{E}_{t}\left[\Lambda_{t: t+1}\left(1+r_{t}^{d}\right)\right]=1
$$

Minimization problem:

$$
\min _{\left\{C_{t}^{\mathrm{BF}}, C_{t}^{\mathrm{SME}}\right\}} P_{t} C_{t}=P_{t}^{\mathrm{SME}} C_{t}^{\mathrm{SME}}+P_{t}^{\mathrm{BF}} C_{t}^{\mathrm{BF}}
$$

(s.t.) Consumption bundle:

$$
C_{t}=\left(\omega^{\frac{1}{\epsilon}} C_{t}^{\mathrm{BF} \frac{\epsilon-1}{\epsilon}}+(1-\omega)^{\frac{1}{\epsilon}} C_{t}^{\mathrm{SME}} \frac{\frac{\epsilon-1}{\epsilon}}{{ }^{\frac{\epsilon}{\epsilon-1}}}\right.
$$

Cost minimization w.r.t. $C_{t}^{\mathrm{BF}}$ :

$$
C_{t}^{\mathrm{BF}}=\omega\left(\frac{P_{t}^{\mathrm{BF}}}{P_{t}}\right)^{-\epsilon} C_{t}
$$


Cost minimization w.r.t. $C_{t}^{\mathrm{SME}}$ :

$$
C_{t}^{S M E}=(1-\omega)\left(\frac{P_{t}^{\mathrm{SME}}}{P_{t}}\right)^{-\epsilon} C_{t}
$$

Implied price index (for reference):

$$
P_{t}=\left(\omega P_{t}^{\mathrm{BF}^{1-\epsilon}}+(1-\omega) P_{t}^{\mathrm{SME}^{1-\epsilon}}\right)^{\frac{1}{1-\epsilon}}
$$

\section{Firms}

Firms objective:

$$
\max _{\left\{N_{t}^{s}, K_{t}^{s}, L_{t}^{s}\right\}_{t=0}^{\infty}} \mathbb{E}_{0}\left[\sum_{t=0}^{\infty} \Lambda_{0: t} \mathrm{DIV}_{t}^{s}\right]
$$

Dividends:

$$
\operatorname{DIV}_{t}^{s}=P_{t}^{s} Y_{t}^{s}-W_{t} N_{t}^{s}-P_{t}\left(I_{t}^{s}+\frac{1}{2} \varphi^{I} K_{t-1}^{s}\left(\frac{I_{t}^{s}}{K_{t-1}^{s}}-\delta\right)^{2}\right)+L_{t}^{s}-L_{t-1}^{s}\left(1+r_{t-1}^{l, s}\right)
$$

Production function:

$$
Y_{t}^{s}=\theta_{t}^{s}\left(K_{t-1}^{s}\right)^{\alpha^{s}}\left(N_{t}^{s}\right)^{1-\alpha^{s}}
$$

Capital law of motion:

$$
K_{t}^{s}=(1-\delta) K_{t-1}^{s}+I_{t}^{s}
$$

Financing demand (with $\Xi_{t}^{s}$ as Lagrange multiplier):

$$
L_{t}^{s}=W_{t} N_{t}^{s}+P_{t} I_{t}^{s}
$$

FOC w.r.t. $N_{t}$ :

$$
W_{t}\left(1+\Xi_{t}^{s}\right)=P_{t}^{s}\left(1-\alpha^{s}\right) \frac{Y_{t}^{s}}{N_{t}^{s}}
$$

FOC w.r.t. $K_{t}$ :

$$
Q_{t}^{s}=\mathbb{E}_{t}\left[\Lambda_{t: t+1}\left(P_{t+1}^{s} \alpha^{s} \frac{Y_{t+1}^{s}}{K_{t}^{s}}+(1-\delta) Q_{t+1}^{s}\right)\right]
$$


FOC w.r.t. $I_{t}$ (Tobin's Q):

$$
\frac{Q_{t}^{s}}{P_{t}}=1+\varphi^{I}\left(\frac{I_{t}^{s}}{K_{t-1}^{s}}-\delta\right)
$$

FOC w.r.t. $L_{t}^{s}$ :

$$
1+\Xi_{t}^{s}=\mathbb{E}_{t}\left[\Lambda_{t: t+1}\left(1+r_{t}^{l, s}\right)\right]
$$

Minimization problem:

$$
\min _{\left\{L_{t}^{s, \mathrm{~GB}}, L_{t}^{s, \mathrm{LB}}\right\}} L_{t}^{s}\left(1+r_{t}^{l, s}\right)=L_{t}^{s, \mathrm{~GB}}\left(1+r_{t}^{l, s, \mathrm{~GB}}\right)+L_{t}^{s, \mathrm{LB}}\left(1+r_{t}^{l, s, \mathrm{LB}}\right)
$$

(s.t.) Borrowing technology:

$$
L_{t}^{s}=\left(\tau^{s \frac{1}{\nu}} L_{t}^{s, \mathrm{~GB} \frac{\nu-1}{\nu}}+\left(1-\tau^{s}\right)^{\frac{1}{\nu}} L_{t}^{s, \mathrm{LB} \frac{\nu-1}{\nu}}\right)^{\frac{\nu}{\nu-1}}
$$

Cost minimization w.r.t. $L_{t}^{s, \mathrm{~GB}}$ :

$$
L_{t}^{s, \mathrm{~GB}}=\tau^{s}\left(\frac{1+r_{t}^{l, s, \mathrm{~GB}}}{1+r_{t}^{l, s}}\right)^{-\nu} L_{t}^{s}
$$

Cost minimization w.r.t. $L_{t}^{s, \mathrm{LB}}$ :

$$
L_{t}^{s, \mathrm{LB}}=\left(1-\tau^{s}\right)\left(\frac{1+r_{t}^{l, s, \mathrm{LB}}}{1+r_{t}^{l, s}}\right)^{-\nu} L_{t}^{s}
$$

Effective interest rate:

$$
1+r_{t}^{l, s}=\left(\tau^{s}\left(1+r_{t}^{l, s, \mathrm{~GB}}\right)^{1-\nu}+\left(1-\tau^{s}\right)\left(1+r_{t}^{l, s, \mathrm{LB}}\right)^{1-\nu}\right)^{\frac{1}{1-\nu}}
$$

\section{Local Bank}

Local bank objective:

$$
\operatorname{Lit}_{t}^{\mathrm{LB}, \mathrm{SME}}, \max _{t}^{\mathrm{LB}, \mathrm{BF}}, D_{t}, M_{t} \Pi_{t}^{\mathrm{LB}}
$$

Balance sheet:

$$
L_{t}^{\mathrm{LB}}=M_{t}+D_{t}
$$


Profits (accruing in the beginning of next period):

$\Pi_{t}^{\mathrm{LB}}=L_{t}^{\mathrm{SME}, \mathrm{LB}} r_{t}^{l, \mathrm{SME}, \mathrm{LB}}+L_{t}^{\mathrm{BF}, \mathrm{LB}} r_{t}^{l, \mathrm{BF}, \mathrm{LB}}-M_{t} r_{t}^{m}-D_{t} r_{t}^{d}-\frac{1}{2} \varphi^{\mathrm{LB}} D\left(\frac{D_{t}-D}{D}\right)^{2}$

FOC w.r.t. $D_{t}$ (comb. with FOC w.r.t. $M_{t}$ ):

$$
r_{t}^{d}=r_{t}^{m}+l b s_{t}-\varphi^{\mathrm{LB}} \frac{D_{t}-D}{D}
$$

FOC w.r.t. $L_{t}^{\mathrm{SME}, \mathrm{LB}}$ (comb. with FOC w.r.t. $M_{t}$ ):

$$
r_{t}^{l, \mathrm{SME}, \mathrm{LB}}=\left(r_{t}^{m}+l b s_{t}\right) M U^{\mathrm{SME}}
$$

FOC w.r.t. $L_{t}^{\mathrm{BF}, \mathrm{LB}}$ (comb. with FOC w.r.t. $M_{t}$ ):

$$
r_{t}^{l, \mathrm{BF}, \mathrm{LB}}=\left(r_{t}^{m}+l b s_{t}\right) M U^{\mathrm{BF}}
$$

Composition of loans to firms:

$$
L_{t}^{\mathrm{LB}}=L^{\mathrm{SME}, \mathrm{LB}}+L^{\mathrm{BF}, \mathrm{LB}}
$$

\section{Global Bank}

Global bank objective:

$$
L_{t}^{\mathrm{GB}, \mathrm{SME}}, L_{t}^{\mathrm{GB}, \mathrm{SME} *}, \max _{t}^{\mathrm{GB}, \mathrm{BF}}, L_{t}^{\mathrm{GB}, \mathrm{BF} *}, M_{t}, M_{t}^{*}, B_{t} \Pi_{t}^{\mathrm{GB}}
$$

Balance sheet:

$$
L_{t}^{\mathrm{GB}}+L_{t}^{\mathrm{GB} *}+M_{t}+M_{t}^{*}=B_{t}
$$

Profits (accruing in the beginning of next period):

$$
\begin{aligned}
\Pi_{t}^{\mathrm{GB}} & =\left(L_{t}^{\mathrm{BF}, \mathrm{GB}}+L_{t}^{\mathrm{BF}, \mathrm{GB} *}\right) r_{t}^{l, \mathrm{BF}, \mathrm{GB}}+\left(L_{t}^{\mathrm{SME}, \mathrm{GB}}+L_{t}^{\mathrm{SME}, \mathrm{GB} *}\right) r_{t}^{l, \mathrm{SME}, \mathrm{GB}}+\left(M_{t}+M_{t}^{*}\right) r_{t}^{m} \\
& -B_{t} r^{b}-\frac{1}{2} \varphi^{\mathrm{GB}} R W A\left(\frac{R W A_{t}-R W A}{R W A}\right)^{2}
\end{aligned}
$$

Risk-weighted assets definition:

$$
R W A_{t}=\gamma^{L}\left(L_{t}^{\mathrm{GB}}+L_{t}^{\mathrm{GB} *}\right)+\gamma^{M}\left(M_{t}+M_{t}^{*}\right)
$$


FOC w.r.t. $L_{t}^{\mathrm{SME}, \mathrm{GB}(*)}$ (comb. with FOC w.r.t. $B_{t}$ ):

$$
r_{t}^{l, \mathrm{SME}, \mathrm{GB}}=\left(r_{t}^{b}+\gamma^{L} \varphi^{\mathrm{GB}}\left(\frac{R W A_{t}-R W A}{R W A}\right)\right) M U^{\mathrm{SME}}
$$

FOC w.r.t. $L_{t}^{\mathrm{BF}, \mathrm{GB}(*)}$ (comb. with FOC w.r.t. $B_{t}$ ):

$$
r_{t}^{l, \mathrm{BF}, \mathrm{LB}}=\left(r_{t}^{b}+\gamma^{L} \varphi^{\mathrm{GB}}\left(\frac{R W A_{t}-R W A}{R W A}\right)\right) M U^{\mathrm{BF}}
$$

FOC w.r.t. $M_{t}^{(*)}$ (comb. with FOC w.r.t. $\left.B_{t}\right)$ :

$$
r_{t}^{m}=r_{t}^{b}+\gamma^{M} \varphi^{\mathrm{GB}}\left(\frac{R W A_{t}-R W A}{R W A}\right)
$$

Composition of loans to firms:

$$
L_{t}^{\mathrm{GB}(*)}=L_{t}^{\mathrm{SME}, \mathrm{GB}(*)}+L_{t}^{\mathrm{BF}, \mathrm{GB}(*)}
$$

\section{Macroeconomy}

GDP:

$$
Y_{t}=\frac{P_{t}^{\mathrm{BF}}}{P_{t}} Y_{t}^{\mathrm{BF}}+\frac{P_{t}^{\mathrm{SME}}}{P_{t}} Y_{t}^{\mathrm{SME}}
$$

Total bank loans:

$$
L_{t}=L_{t}^{\mathrm{GB}}+L_{t}^{\mathrm{LB}}
$$

SME share:

$$
\mathrm{SME}_{t}=\frac{P_{t}^{\mathrm{SME}} Y_{t}^{\mathrm{SME}}}{P_{t} Y_{t}}
$$

Domestic bank dependence:

$$
\mathrm{DBD}_{t}=\frac{L_{t}^{\mathrm{LB}}}{L_{t}^{\mathrm{LB}}+L_{t}^{\mathrm{GB}}}
$$

Total net costs:

$$
\Gamma_{t}=\left(L_{t}^{\mathrm{SME}, \mathrm{GB}}+L_{t}^{\mathrm{SME}, \mathrm{LB}}-L_{t}^{\mathrm{SME}}\right)+\left(L_{t}^{\mathrm{BF}, \mathrm{GB}}+L_{t}^{\mathrm{BF}, \mathrm{LB}}-L_{t}^{\mathrm{BF}}\right)+O(2)
$$


Price normalization:

$$
P_{t}^{\mathrm{BF}}=1
$$

Current account:

$$
C A_{t}=-\Delta M_{t}-\Delta L_{t}^{\mathrm{GB}}
$$

Net exports:

$$
N X_{t}=C A_{t}-\left(-L_{t-1}^{\mathrm{BF}, \mathrm{GB}} r_{t-1}^{\mathrm{BF}, \mathrm{GB}}-L_{t-1}^{\mathrm{SME}, \mathrm{GB}} r_{t-1}^{\mathrm{SME}, \mathrm{GB}}-M_{t-1} r_{t-1}^{m}+\mu^{\mathrm{GB}} \Pi_{t-1}^{\mathrm{GB}}\right)
$$

\section{Market Clearing}

Current account to ROW:

$$
C A_{t}=-\Delta B_{t}
$$

Net exports to ROW:

$$
N X_{t}=C A_{t}+B_{t-1} r_{t-1}^{b}
$$

Labor:

$$
N_{t}=N_{t}^{\mathrm{BF}}+N_{t}^{\mathrm{SME}}
$$

Investment:

$$
I_{t}=I_{t}^{\mathrm{BF}}+I_{t}^{\mathrm{SME}}
$$

Capital:

$$
K_{t}=K_{t}^{\mathrm{BF}}+K_{t}^{\mathrm{SME}}
$$

Non-tradable good:

$$
Y_{t}^{\mathrm{SME}}=(1-\omega)\left(\frac{P_{t}^{\mathrm{SME}}}{P_{t}}\right)^{-\epsilon}\left(C_{t}+I_{t}+\frac{\Gamma_{t}}{P_{t}}\right)
$$

Tradable good (Follows from Walras Law):

$$
Y_{t}^{\mathrm{BF}}=\omega\left(\frac{P_{t}^{\mathrm{BF}}}{P_{t}}\right)^{-\epsilon}\left(C_{t}+I_{t}+\frac{\Gamma_{t}}{P_{t}}\right)+\frac{N X_{t}}{P_{t}^{\mathrm{BF}}}
$$




\section{Exogenous Processes}

Sectoral TFP shocks (home):

$$
\log \theta_{t}^{s}=\rho^{\theta} \log \theta_{t-1}^{s}-\sigma^{s}\left(\frac{\rho^{\dagger}}{\alpha^{\dagger}} \eta_{t}^{s, \dagger}+\sqrt{1-\left(\frac{\rho^{\dagger}}{\alpha^{\dagger}}\right)^{2}} \eta_{t}^{s}\right)
$$

Sectoral TFP (foreign, i.e. "rest-of-EMU”):

$$
\log \theta_{t}^{s *}=\rho^{\theta} \log \theta_{t-1}^{s *}-\alpha^{\dagger} \sigma^{s} \eta_{t}^{s, \dagger}
$$

where $\eta_{t}^{s, \dagger}, \eta_{t}^{s} \stackrel{i . i . d .}{\sim} \mathcal{N}(0,1)$.

Local banking shocks (home):

$$
l b s_{t}=\rho^{l b s} l b s_{t-1}+\sigma^{l b s}\left(\frac{\rho^{\dagger}}{\alpha^{\dagger}} \eta_{t}^{l b s, \dagger}+\sqrt{1-\left(\frac{\rho^{\dagger}}{\alpha^{\dagger}}\right)^{2}} \eta_{t}^{l b s}\right),
$$

Local banking shocks(foreign, i.e. "rest-of-EMU”):

$$
l b s_{t}^{*}=\rho^{l b s} l b s_{t-1}^{*}+\alpha^{\dagger} \sigma^{l b s} \eta_{t}^{l b s, \dagger}
$$

where $\eta_{t}^{l b s, \dagger}, \eta_{t}^{l b s} \stackrel{i . i . d .}{\sim} \mathcal{N}(0,1)$ and for each country $c$ (the simulation country) $\alpha_{c}^{\dagger}=$ $\left(\omega_{c}^{\prime} \Omega \omega_{c}\right)^{\frac{1}{2}}, \omega_{c}=\operatorname{vec}\left(\frac{G D P_{j}}{\sum_{j \neq c} G D P_{j}}\right)$, and $\Omega=\left[\begin{array}{ccc}1 & \cdots & \rho^{\dagger} \\ \vdots & \ddots & \vdots \\ \rho^{\dagger} & \cdots & 1\end{array}\right]$.

Global banking shock:

$$
\log B_{t}=\left(1-\rho^{g b s}\right) \log B+\rho^{g b s} \log B_{t-1}-\sigma^{g b s} \eta_{t}^{g b s}
$$

where $\eta_{t}^{g b s} \stackrel{i . i . d .}{\sim} \mathcal{N}(0,1)$. 